\title{
Zonal asymmetries in middle atmospheric ozone and water vapour derived from Odin satellite data 2001-2010
}

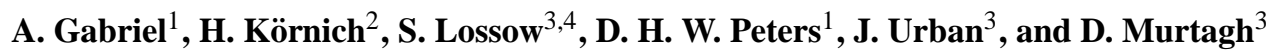 \\ ${ }^{1}$ Leibniz-Institute for Atmospheric Physics at the University Rostock, Schlossstr. 6, 18225 Kühlungsborn, Germany \\ ${ }^{2}$ Department of Meteorology, Stockholms University, 10691 Stockholm, Sweden \\ ${ }^{3}$ Chalmers University of Technology, Department of Earth and Space Sciences, Hörsalsvägen 11, 41296 Göteborg, Sweden \\ ${ }^{4}$ Institute of Meteorology and Climate Research, Karlsruhe Institute of Technology, 76021 Karlsruhe
}

Received: 2 December 2010 - Published in Atmos. Chem. Phys. Discuss.: 4 February 2011

Revised: 16 September 2011 - Accepted: 19 September 2011 - Published: 26 September 2011

\begin{abstract}
Stationary wave patterns in middle atmospheric ozone $\left(\mathrm{O}_{3}\right)$ and water vapour $\left(\mathrm{H}_{2} \mathrm{O}\right)$ are an important factor in the atmospheric circulation, but there is a strong gap in diagnosing and understanding their configuration and origin. Based on Odin satellite data from 2001 to 2010 we investigate the stationary wave patterns in $\mathrm{O}_{3}$ and $\mathrm{H}_{2} \mathrm{O}$ as indicated by the seasonal long-term means of the zonally asymmetric components $\mathrm{O}_{3}^{*}=\mathrm{O}_{3}-\left[\mathrm{O}_{3}\right]$ and $\mathrm{H}_{2} \mathrm{O}^{*}=\mathrm{H}_{2} \mathrm{O}-\left[\mathrm{H}_{2} \mathrm{O}\right]\left(\left[\mathrm{O}_{3}\right]\right.$, $\left[\mathrm{H}_{2} \mathrm{O}\right]$ : zonal means). At mid- and polar latitudes we find a pronounced wave one pattern in both constituents. In the Northern Hemisphere, the wave patterns increase during autumn, maintain their strength during winter and decay during spring, with maximum amplitudes of about $10-20 \%$ of the zonal mean values. During winter, the wave one in $\mathrm{O}_{3}^{*}$ shows a maximum over the North Pacific/Aleutians and a minimum over the North Atlantic/Northern Europe and a double-peak structure with enhanced amplitude in the lower and in the upper stratosphere. The wave one in $\mathrm{H}_{2} \mathrm{O}^{*}$ extends from the lower stratosphere to the upper mesosphere with a westward shift in phase with increasing height including a jump in phase at upper stratosphere altitudes. In the Southern Hemisphere, similar wave patterns occur mainly during southern spring. By comparing the observed wave patterns in $\mathrm{O}_{3}^{*}$ and $\mathrm{H}_{2} \mathrm{O}^{*}$ with a linear solution of a steady-state transport equation for a zonally asymmetric tracer component we find that these wave patterns are primarily due to zonally asymmetric transport by geostrophically balanced winds, which are derived from observed temperature profiles. In addition
\end{abstract}

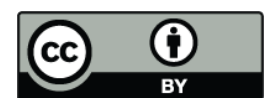

Correspondence to: A. Gabriel (gabriel@iap-kborn.de) temperature-dependent photochemistry contributes substantially to the spatial structure of the wave pattern in $\mathrm{O}_{3}^{*}$. Further influences, e.g., zonal asymmetries in eddy mixing processes, are discussed.

\section{Introduction}

During recent years several investigations have been carried out to examine the possible influence of stationary wave patterns in stratospheric ozone $\left(\mathrm{O}_{3}\right)$ on the atmospheric circulation, based on general circulation model studies with assimilated ozone data and with interactive chemistry (Kirchner and Peters, 2003; Sassi et al., 2005; Gabriel et al., 2007; Crook et al., 2008; Gillett et al., 2009; Waugh et al., 2009). Stationary wave patterns in middle atmospheric water vapour $\left(\mathrm{H}_{2} \mathrm{O}\right)$ may also contribute importantly to the atmospheric circulation, but to our knowledge this has not been investigated up to now. On the other hand, there is a strong gap in the knowledge of the spatial structure of the stationary wave patterns in middle atmospheric $\mathrm{O}_{3}$ and $\mathrm{H}_{2} \mathrm{O}$ based on model-independent observations, and in understanding the processes which generate these wave patterns. In this context, the first aim of this paper is to present stationary wave patterns in middle atmospheric $\mathrm{O}_{3}$ and $\mathrm{H}_{2} \mathrm{O}$ derived from Odin satellite data between 2001 and 2010. A second aim is to use a linear approach of a steady-state transport equation for a zonally asymmetric tracer component to specify the effects of mean transport by advection, which helps to identify the most important processes that generate the observed wave patterns. 
Quasi-stationary planetary wave patterns in temperature or geopotential are a well known feature of the extra-tropical middle atmosphere (e.g., Andrews et al., 1987). In the Northern Hemisphere, a quasi-stationary wave pattern with a pronounced zonal wave number one (wave one pattern) usually occurs during winter, and is related to the zonal asymmetry of the stratospheric polar vortex, i.e. to Aleutian high and polar low anomalies in geopotential height (note that the centre of the polar vortex occurs most frequently over North-Eastern Europe/Western Siberia, as found by Waugh and Randel, 1999 and Karpetchko et al., 2005). Other wave modes (particularly wave two and wave three) are usually much less pronounced but they increase strongly in connection with sudden stratospheric warming events (SSWs) or during final vortex break-up periods. The common understanding is that planetary waves, which are forced in the troposphere by large mountain ridges, land-ocean contrasts or longitudedependent heat sources, propagate vertically within mean westerly but not easterly flow into the middle atmosphere where they generate quasi-stationary wave patterns (Charney and Drazin, 1961). In the mesosphere, zonal asymmetries in gravity wave breaking may also play an important role in configuring stationary wave patterns (e.g., Smith, 2003).

Planetary waves play an essential role in driving the zonal mean transport by the Brewer-Dobson circulation and eddy mixing processes, i.e. the zonal mean meridional transport of trace gases from the tropics to mid- and polar latitudes (Tung, 1982; Holton, 1985; Andrews et al., 1987). Important efforts have been made to understand and to quantify the contributions of the transport processes to the mean seasonal cycle and to the long-term variations in the zonal mean distributions of stratospheric ozone and water vapour (WMO, 2007; SPARC Report No. 2, 2000). However, zonal asymmetries in the mean meridional transport and their role in configuring the stationary wave patterns in $\mathrm{O}_{3}$ and $\mathrm{H}_{2} \mathrm{O}$ have been examined only very sparsely up to now.

Mean concentrations of water vapour $\left(\mathrm{H}_{2} \mathrm{O}\right)$ decrease very rapidly in the upper troposphere/lowermost stratosphere region (Holton and Gettelmann, 2001) and increase then again up to maximum values around the stratopause because of the oxidation of methane $\left(\mathrm{CH}_{4}\right)$, which is transported from the troposphere into the stratosphere (e.g., Brasseur and Solomon, 1995; SPARC Report No. 2, 2000). Based on satellite data from the Halogen Occultation Experiment (HALOE) on the Upper Atmosphere Research Satellite (UARS), Randel et al. (1998) reveal the influence of zonal mean transport processes on the seasonal cycle and long-term variations of stratospheric $\mathrm{CH}_{4}$ and $\mathrm{H}_{2} \mathrm{O}$. In the mesosphere, where the concentrations of $\mathrm{H}_{2} \mathrm{O}$ decrease with height because it is slowly photolysed and depleted via reaction with atomic oxygen (e.g., Brasseur and Solomon, 1995), the zonal mean $\mathrm{H}_{2} \mathrm{O}$ distribution at a given vertical level results mainly from the mean annual cycle in zonal mean meridional transport, as shown by Lossow et al. (2009) diagnosing Odin satellite data and chemistry-climate model calculations. Cli- mate model simulations suggest that the observed increase of stratospheric water vapour of about $20-50 \%$ between the 1960s and 1990s, which was included in the model simulations via a parameterized methane oxidation scheme, may have significantly contributed to the observed change in the atmospheric circulation pattern of the North Atlantic Oscillation (Joshi et al., 2006). These results underline the importance of adequate three-dimensional water vapour distributions in climate models and, hence, the requirement of diagnosing and understanding the zonal asymmetries in observed stratospheric water vapour.

In the lower and middle stratosphere $\mathrm{O}_{3}$ is controlled mainly dynamically by transport processes where its chemical lifetime is relatively long, but controlled mainly photochemically in the upper stratosphere and mesosphere where its chemical lifetime is relatively short (e.g., Garcia and Hartmann, 1980; Stolarski and Douglass, 1985; Nathan et al., 1994). Therefore, both transport processes and temperaturedependent chemistry play an important role in determining the stationary wave patterns in $\mathrm{O}_{3}$. Detailed examinations of ozone-temperature correlations based on photochemical models and satellite data suggest a height-dependent relation between wave perturbations in upper stratospheric ozone photochemistry and temperature (e.g., Rood and Douglass, 1985; Douglass et al., 1985; Froidevaux et al., 1989; Brasseur and Solomon, 1995; Smith 1995; Ward et al., 2010). Similar relations were also found in wave perturbations in the equatorial stratosphere (Randel, 1990; Sun and Leovy, 1990; Mote and Dunkerton, 2004) and during SSWs (e.g., Wang et al., 2005). In particular, the catalytic ozone destruction cycles involving the nitrogen $\left(\mathrm{NO}_{\mathrm{x}}\right)$, hydrogen $\left(\mathrm{HO}_{\mathrm{x}}\right)$, chlorine $\left(\mathrm{ClO}_{\mathrm{x}}\right)$ and bromine $\left(\mathrm{BrO}_{\mathrm{x}}\right)$ radicals play an important role in determining the stratospheric ozone distribution (e.g., Brasseur and Solomon, 1995; WMO, 2007, and references therein). In the lower stratosphere, temperaturedependent chlorine and bromine chemistry could amplify the zonal asymmetries in the ozone destruction rates in case of a pre-existing stationary wave pattern in temperature, e.g., in case of a zonally asymmetric configuration of the cold winter polar vortex. In the upper stratosphere, the temperaturedependence of the $\mathrm{NO}_{\mathrm{x}}$ catalytic ozone destruction cycle becomes important for ozone changes because of higher mean temperatures, for example during major sudden stratospheric warming events (Stolarski and Douglass, 1985; Flury et al., 2009).

Several two- and three-dimensional model investigations have also shown that planetary waves have a strong influence on ozone transport and temperature-dependent ozone chemistry (e.g., Austin and Butchart, 1992; Solomon et al., 1998; Kinnersley and Tung, 1998; Gabriel and Schmitz, 2003). The influence of planetary wave patterns on the longitudedependent distribution of total column ozone was demonstrated based on simplified approaches of tracer transport for the lower stratosphere (Hood and Zaff, 1995; Peters and Entzian, 1996, 1999). Stationary wave one patterns or zonal 
Table 1. Overview of those data of the Odin satellite measurements between June 2001 and April 2010 that are used in this paper; note that the profiles are irregularly spaced over the Northern and Southern Hemisphere, and that the number of profiles per month varies slightly from year to year; for the $489 \mathrm{GHz}$ emission line we use $\mathrm{H}_{2} \mathrm{O}$ data only for the stratosphere (up to $50 \mathrm{~km}$ ); for more details see Sect. 2.1.

\begin{tabular}{clcl}
\hline Emission line & Product & Number of profiles & Altitude range \\
\hline $489 \mathrm{GHz}$ & $\mathrm{H}_{2} \mathrm{O}$ & 119690 & $20-75 \mathrm{~km}($ used up to $50 \mathrm{~km})$ \\
$544 \mathrm{GHz}$ & $\mathrm{O}_{3}$ & 600667 & $20-75 \mathrm{~km}$ \\
$557 \mathrm{GHz}$ & $\mathrm{H}_{2} \mathrm{O}, T$ & 132572 & $50-100 \mathrm{~km}, 50-90 \mathrm{~km}$ \\
\hline
\end{tabular}

asymmetries in stratospheric ozone were found in assimilated ozone of European Centre of Medium-Range Weather Forecasts (ECMWF) Reanalysis data (Gabriel et al., 2007), and their decadal variations were found to be coherent with decadal variations in upper tropospheric geopotential height (Peters et al., 2008). However, as in the case of water vapour, more research based on model-independent observations is required to understand the processes responsible for the quasi-stationary wave patterns in the three-dimensional stratospheric ozone distribution.

During the last two decades more and more accurate satellite data have become available which provide a new perspective to investigate the three-dimensional wave patterns. The Odin satellite, which was launched in 2001 and which is currently still operational, provides such suitable information throughout the middle atmosphere (Urban et al., 2007, Lossow et al., 2008, 2009; Jones et al., 2009). We use this data to derive long-term means of quasi-stationary wave patterns in stratospheric ozone and stratospheric and mesospheric water vapour, as indicated by the zonal asymmetries $\mathrm{O}_{3}^{*}=\mathrm{O}_{3}-\left[\mathrm{O}_{3}\right]$ and $\mathrm{H}_{2} \mathrm{O}^{*}=\mathrm{H}_{2} \mathrm{O}-\left[\mathrm{H}_{2} \mathrm{O}\right]\left(\left[\mathrm{O}_{3}\right]\right.$, $\left[\mathrm{H}_{2} \mathrm{O}\right]$ : zonal means). The results are presented in Sect. 2, together with the wave patterns in temperature and geostrophically balanced winds for the time period 2001-2010 as derived from combined temperature profiles of Odin and ECMWF Reanalysis (ERA Interim) data. In Sect. 3 we use these winds for a linear solution of a steady-state transport equation for the zonally asymmetric component of a chemical tracer in order to determine the importance of the individual processes (advection, eddy mixing and chemistry) which configure these wave patterns. Summary and discussion are given in Sect. 4, and conclusions in Sect. 5.

\section{Diagnosis of zonal asymmetries in ozone, water vapour and temperature}

\subsection{Data}

The Odin satellite was launched in 2001 as a joint venture of Sweden, Canada, Finland and France (Murtagh et al., 2002), and is currently still operational as an European Space Agency (ESA) third party mission. Odin uses a sunsynchronous polar $\left(82.5^{\circ} \mathrm{S}\right.$ to $\left.82.5^{\circ} \mathrm{N}\right)$ orbit and carries two instruments, i.e. the Sub-Millimetre Radiometer (SMR) and the Optical Spectrograph InfraRed Imager System (OSIRIS), providing, amongst others, measurements of ozone, water vapour and temperature in the middle atmosphere. Some more details of Odin SMR and the retrievals can be found, for example, in Urban et al. (2005) and Lossow et al. (2007). The Odin data have been widely used to diagnose middle atmospheric ozone and water vapour (e.g., Urban et al., 2007; Lossow et al., 2008, 2009; Jones et al. 2009).

For this paper, we combine data sets for the time period 2001 to 2010 derived from measurements at different emission lines, which provide a large number of irregularly spaced profiles to diagnose the seasonal mean stationary wave patterns in ozone, water vapour and temperature. The vertical resolution of the profiles is $\sim 3-3.5 \mathrm{~km}$ for water vapour, $\sim 2-3 \mathrm{~km}$ for ozone and $\sim 4-5 \mathrm{~km}$ for temperature (Urban et al., 2005; Lossow et al., 2007). For data handling all of the profiles are interpolated in the vertical to a grid with resolution of $1 \mathrm{~km}$.

We sort the local irregularly spaced profiles as a function of season and location on a homogeneous $10^{\circ} \times 10^{\circ}$ latitudelongitude grid extending from $180^{\circ} \mathrm{W}$ to $180^{\circ} \mathrm{E}$ and from $80^{\circ} \mathrm{S}$ to $80^{\circ} \mathrm{N}$. Then we calculate an average over the profiles that are located in a specific grid box. As a result we obtain a mean seasonal profile for each grid box of the $10^{\circ} \times 10^{\circ}$ latitude-longitude grid. An overview of the data sets we use is given in Table 1. For water vapour, the measurements of the $489 \mathrm{GHz}$ emission line provide 119690 profiles covering altitudes between $20 \mathrm{~km}$ and $75 \mathrm{~km}$ (here we use only stratospheric data up to $50 \mathrm{~km}$ ), and the measurements of the $557 \mathrm{GHz}$ emission line provide 132572 profiles covering altitudes between $50 \mathrm{~km}$ and $100 \mathrm{~km}$. For stratospheric ozone, measurements of the $544 \mathrm{GHz}$ emission line provide 600667 profiles covering altitudes between $20 \mathrm{~km}$ and $75 \mathrm{~km}$. As for mesospheric water vapour information, the temperature field was derived from the measurements of the $557 \mathrm{GHz}$ band which provide 132572 temperature profiles covering altitudes between $50 \mathrm{~km}$ and $90 \mathrm{~km}$. Overall, the data profile densities represent a horizontal resolution of about 1200 irregularly spaced data profiles per month for water vapour and temperature and about 5600 irregularly spaced data profiles per month for ozone for the time period of June 2001 to April 2010.

After calculating the seasonal long-term means on the $10^{\circ} \times 10^{\circ}$ grid, we derive the zonal mean and the zonally 
(a) $\mathrm{O}_{3}{ }^{*}$ [ppmv] SON ODIN $60 \mathrm{~N}$ 2001-10

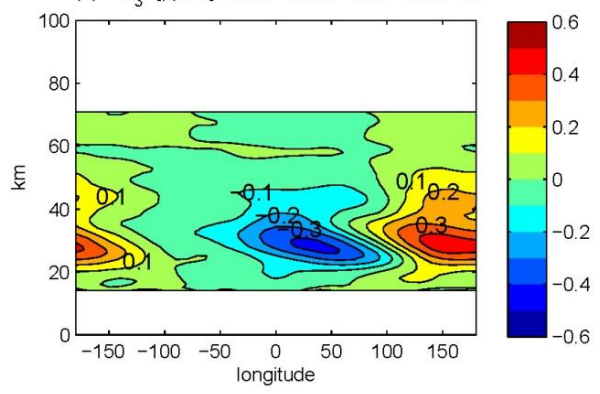

(c) $\mathrm{O}_{3}{ }^{*}$ [ppmv] MAM ODIN $60 \mathrm{~N}$ 2001-10

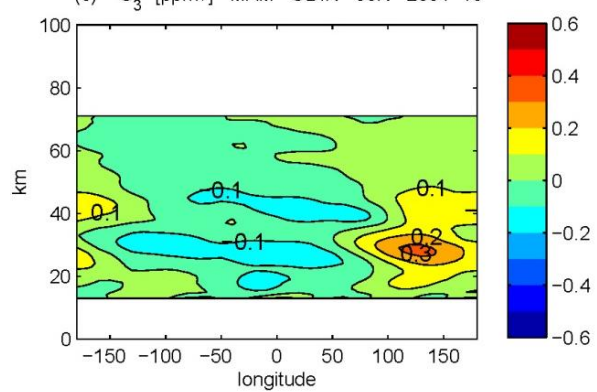

(b) $\mathrm{O}_{3}{ }^{*}$ [ppmv] DJF ODIN $60 \mathrm{~N}$ 2001-10
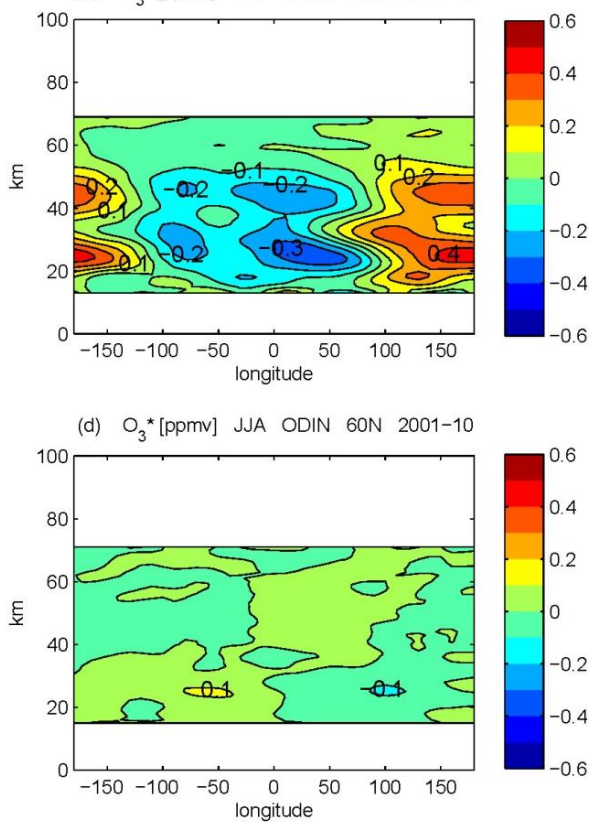

Fig. 1.1. Long-term means of the zonally asymmetric component in volume mixing ratio of ozone $\mathrm{O}_{3}^{*}=\mathrm{O}_{3}-\left[\mathrm{O}_{3}\right]$ (in ppm: parts per million) at $60^{\circ} \mathrm{N}$ for different seasons of the time period 2001-2010; (a) autumn (SON: September-October-November), (b) winter (DJF: DecemberJanuary-February), (c) spring (MAM: March-April-May) and (d) summer (JJA: June-July-August); contour interval: 0.1 ppmv (red colours refer to maximum positive values, blue colours refer to minimum negative values).

asymmetric components of $\mathrm{O}_{3}, \mathrm{H}_{2} \mathrm{O}$ and temperature $T$. Then the zonal mean and the zonally asymmetric fields of water vapour derived from the different emission lines are matched by setting the values at $50 \mathrm{~km}$ to the mean of the values at $49 \mathrm{~km}$ and $51 \mathrm{~km}$ and by applying a 3-point running mean between $48 \mathrm{~km}$ and $52 \mathrm{~km}$, which avoids some spurious effects in the picture of the stationary wave patterns. For illustration, and for comparison with the stationary wave patterns shown in Sect. 2.2 (Fig. 2.1b), the un-matched fields of zonally asymmetric water vapour are shown in the Appendix A.

Additionally, the seasonal mean temperature derived from Odin is combined with the seasonal mean temperature for the same time period as derived from ECMWF Reanalysis (ERA Interim), covering altitudes between $1000 \mathrm{hPa}$ and $1 \mathrm{hPa}$. For consistency the temperature profiles of ERA Interim were transformed to a $10^{\circ} \times 10^{\circ}$ grid using the same procedure as for the Odin data profiles. We match the two temperature fields at stratopause altitudes $(\sim 50 \mathrm{~km})$ analogously to the procedure of the two water vapour fields, but by setting the values around $50 \mathrm{~km}$ to the mean values of $48 \mathrm{~km}$ and $52 \mathrm{~km}$ excluding very strong differences between temperatures at the lowermost level of Odin temperature data at $50 \mathrm{~km}$ and at the upper level of the ERA-Interim data at $1 \mathrm{hPa}$. As for water vapour, the un-matched fields of zonally asymmetric temperature are shown in the Appendix A (compare with Fig. 3.1a).
Note here that, because of the sun-synchronous orbit, Odin makes night-time observations in the winter hemisphere and day-time observations in the summer hemisphere. This feature could have an effect on the derived long-term means because of the diurnal variations in ozone and water in the mesosphere, e.g., due to mesospheric ozone chemistry and tides. However, in this study we focus on the stationary wave patterns in stratospheric ozone, which can assumed to be mainly affected by perturbations in transport and temperature due to vertically propagating planetary waves in time scales of several days to weeks (e.g., Randel, 1993; Coy et al., 2003). The effect of upper mesospheric/lower thermospheric tides on water vapour is not considered here because the strongest amplitudes in the stationary wave patterns of $\mathrm{H}_{2} \mathrm{O}^{*}$ are observed below $80 \mathrm{~km}$, as shown in the next section. Note also that the derived fields are slightly smoothed in space by a $3 \times 3$ grid box filter to filter out local small-scale perturbations.

\subsection{Zonal asymmetries in ozone and water vapour}

Figures 1.1-1.2 and 2.1-2.2 show zonally asymmetric ozone $\left(\mathrm{O}_{3}^{*}\right)$ and water vapour $\left(\mathrm{H}_{2} \mathrm{O}^{*}\right)$ for different seasons at $60^{\circ} \mathrm{N}$ and at $60^{\circ} \mathrm{S}$. Note here that the amplitude of the stratospheric wave one pattern is strongest at the edge of the winter polar vortex, i.e. at latitudes around $60^{\circ} \mathrm{N}$ or $60^{\circ} \mathrm{S}$. During northern winter the amplitudes of the wave one patterns are about $10-20 \%$ of the zonal mean values. 
(a) $\mathrm{O}_{3}{ }^{*}[\mathrm{ppmv}]$ SON ODIN $60 \mathrm{~S} \quad 2001-10$

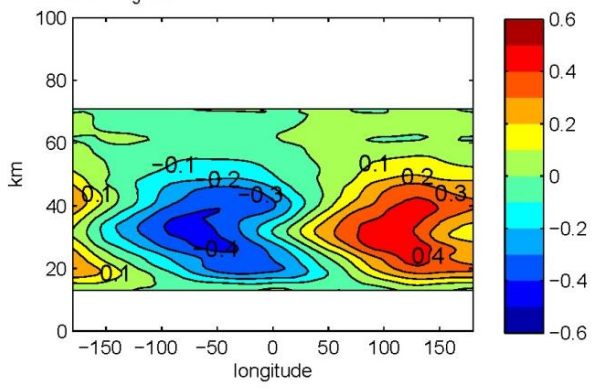

(c) $\mathrm{O}_{3}{ }^{*}$ [ppmv] MAM ODIN 605 2001-10

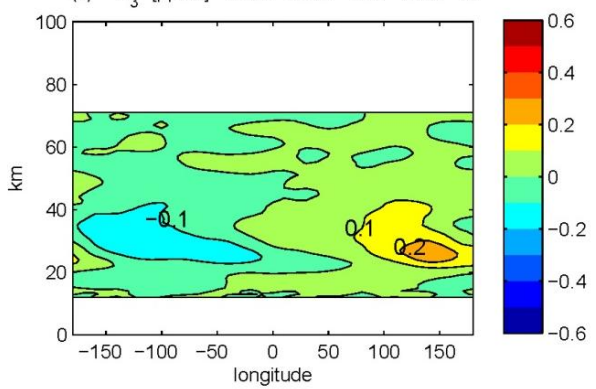

(b) $\mathrm{O}_{3}{ }^{*}[\mathrm{ppm}$ ] DJF ODIN $60 \mathrm{~S} 2001-10$

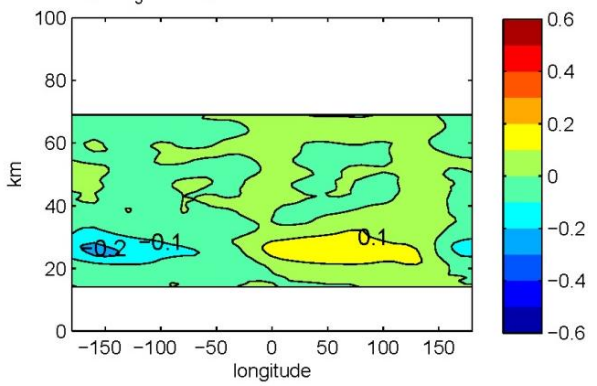

(d) $\mathrm{O}_{3}{ }^{*}[\mathrm{ppmv}]$ JJA ODIN $60 \mathrm{~S}$ 2001-10

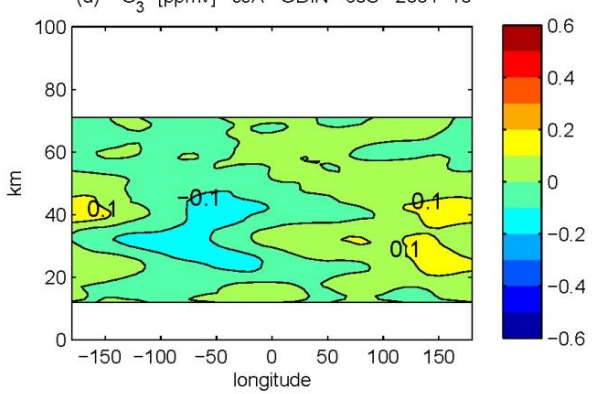

Fig. 1.2. Long-term means of zonally asymmetric ozone $\mathrm{O}_{3}^{*}$ for different seasons similar to Fig. 1.1, but at $60^{\circ} \mathrm{S}$; (a) spring (SON: SeptemberOctober-November), (b) summer (DJF: December-January-February), (c) autumn (MAM: March-April-May) and (d) winter (JJA: June-JulyAugust); contour interval: $0.1 \mathrm{ppmv}$ (red colours refer to maximum positive values, blue colours refer to minimum negative values).

Figure 1.1 illustrates that, in the Northern Hemisphere, the wave one pattern builds up during autumn (SON: September, October, November) is maintained during winter (DJF: December, January, February) and decays during spring (MAM: March, April, May). During summer (JJA: June, July, August) there are only minor planetary wave patterns in the lower stratosphere which might be due to zonal asymmetries in eddy mixing processes in the upper troposphere/lower stratosphere (UTLS) region induced by synoptic-scale baroclinic waves. In relation to previous works (e.g., Garcia and Hartmann, 1980; Stolarski and Douglass, 1985; Nathan et al., 1994; Rood and Douglass, 1985; Douglass et al., 1985; Froidevaux et al., 1989; Peters and Entzian, 1999) both the double-peak structure of $\mathrm{O}_{3}^{*}$ in the vertical occurring during winter, with pronounced amplitude in the lower and the upper stratosphere, and the fact that the wave one pattern of $\mathrm{O}_{3}^{*}$ does not show a westward shift in phase with increasing height (as shown by Fig. 1.1b), as usually found in other quantities like temperature or geopotential height, can be interpreted as a combination of transport processes in the lower and middle stratosphere (where the chemical lifetime of ozone is long and ozone and temperature are correlated), and temperaturedependent chemistry in the upper stratosphere (where the lifetime of ozone is short and ozone and temperature are anticorrelated). In Sect. 3 these processes are discussed in detail.

In the Southern Hemisphere a wave one structure in $\mathrm{O}_{3}^{*}$ develops mainly during southern spring ( $\mathrm{SON})$, as shown in
Fig. 1.2. Here we have to consider that the southern winter polar vortex is usually much more stable and more zonally symmetric than the northern winter polar vortex and that the final break-up of the vortex during spring occurs usually later in the Southern than in the Northern Hemisphere. In this context the effect of heterogeneous chemistry on Polar Stratospheric Cloud (PSC) droplets and related ozone depletions (e.g., Solomon, 1999; WMO, 2007) is more efficient in the Southern than in the Northern Hemisphere. Therefore, the amplitude of the stationary wave one pattern is less pronounced during southern winter (JJA) but more pronounced during southern spring (SON), as also discussed by Crook et al. (2008). As for the Northern Hemisphere, the stationary wave pattern in $\mathrm{O}_{3}^{*}$ during southern summer (DJF) is very weak and might be related to zonal asymmetries in eddy mixing processes induced by synoptic-scale baroclinic waves.

In the Northern Hemisphere, $\mathrm{H}_{2} \mathrm{O}^{*}$ shows also a pronounced wave one pattern during autumn and winter in the mesosphere up to an altitude of about $80 \mathrm{~km}$ and with a strong jump in phase at upper stratosphere altitudes, i.e. at about 40-45 km (Fig. 2.1). In Sect. 3 we show that this wave pattern in $\mathrm{H}_{2} \mathrm{O}^{*}$ is controlled primarily by mean advection. Note here that the matching procedure for $\mathrm{H}_{2} \mathrm{O}^{*}$ at specific levels around $50 \mathrm{~km}$ does not have an effect on the jump in phase at stratopause altitudes which extends over several kilometres. For comparison, Appendix A shows the field of $\mathrm{H}_{2} \mathrm{O}^{*}$ at $60^{\circ} \mathrm{N}$ without applying the matching procedure. 

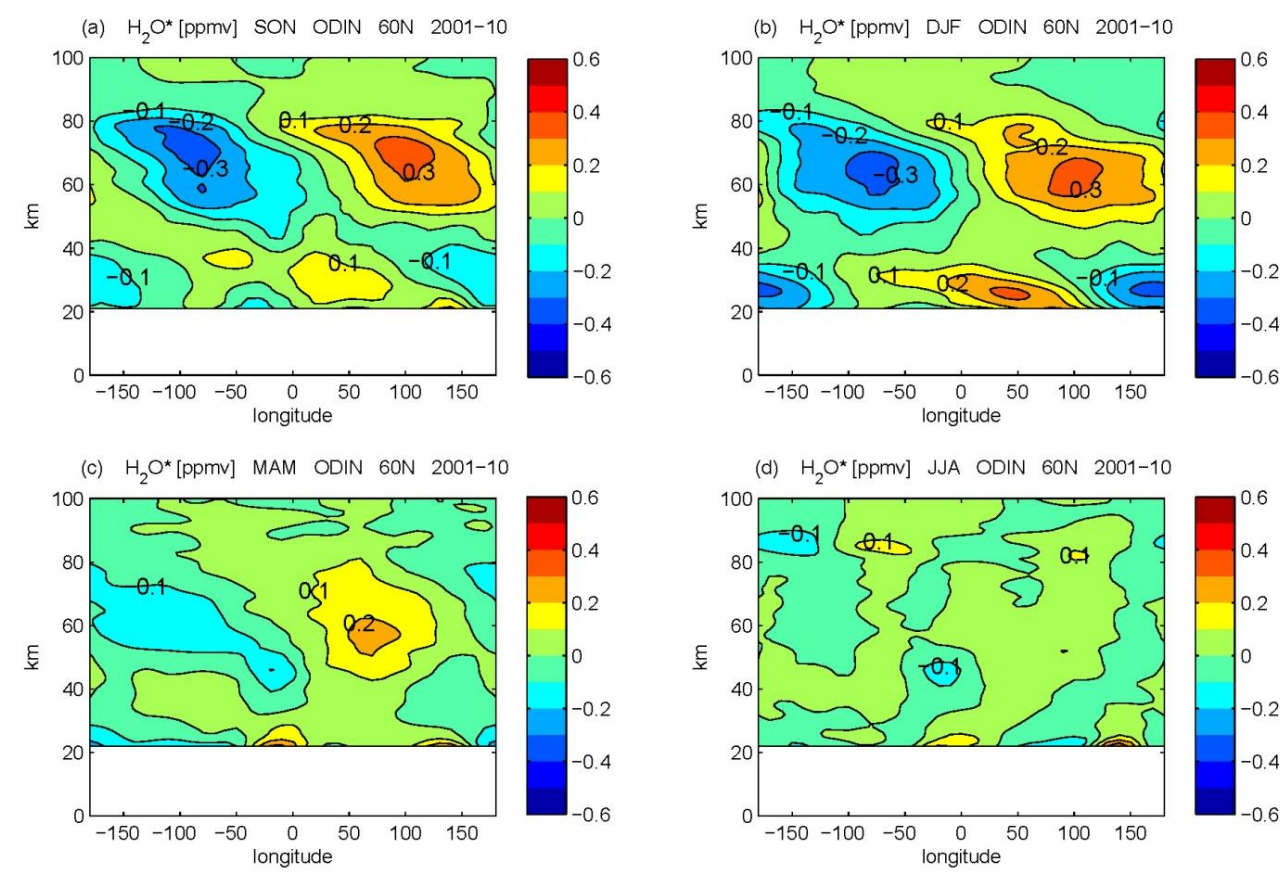

Fig. 2.1. Long-term means of the zonally asymmetric component in volume mixing ratio of water vapour $\mathrm{H}_{2} \mathrm{O}^{*}=\mathrm{H}_{2} \mathrm{O}-\left[\mathrm{H}_{2} \mathrm{O}\right]($ in $p p m$ : parts per million) at $60^{\circ} \mathrm{N}$ for different seasons of the time period 2001-2010; (a) autumn (SON: September-October-November), (b) winter (DJF: December-January-February), (c) spring (MAM: March-April-May) and (d) summer (JJA: June-July-August); contour interval: 0.1 ppmv (red colours refer to maximum positive values, blue colours refer to minimum negative values).

(a) $\mathrm{H}_{2} \mathrm{O}^{*}[\mathrm{ppmv}] \mathrm{SON}$ ODIN $60 \mathrm{~S} 2001-10$

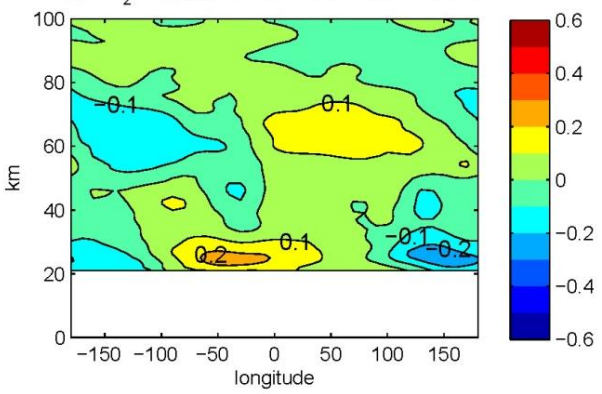

(c) $\mathrm{H}_{2} \mathrm{O}^{*}[\mathrm{ppmv}]$ MAM ODIN $60 \mathrm{~S} 2001-10$

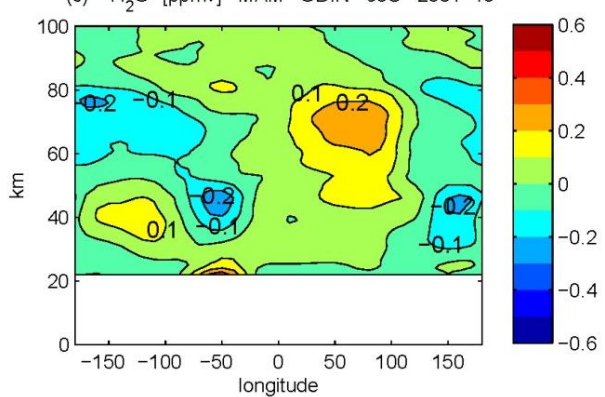

(b) $\mathrm{H}_{2} \mathrm{O}^{*}$ [ppmv] DJF ODIN $60 \mathrm{~S}$ 2001-10

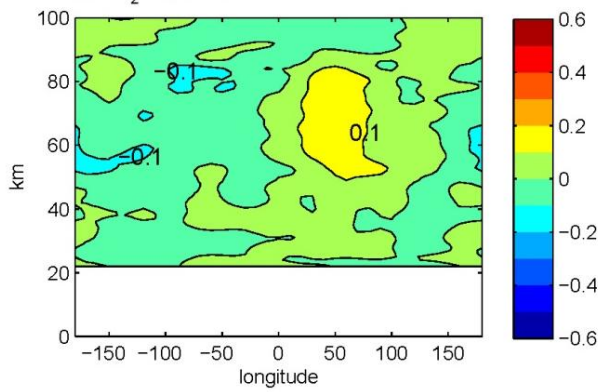

(d) $\mathrm{H}_{2} \mathrm{O}^{*}[\mathrm{ppmv}]$ JJA ODIN $60 \mathrm{~S}$ 2001-10

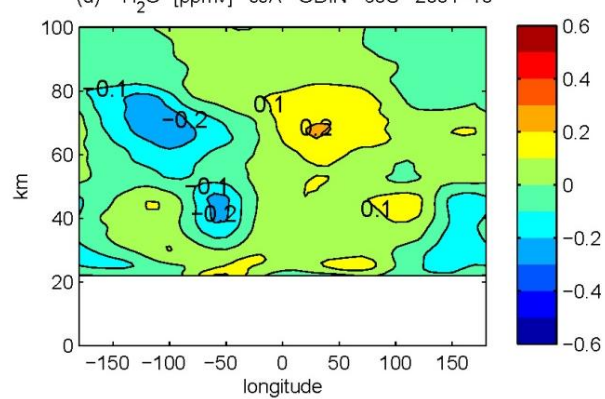

Fig. 2.2. Long-term means of zonally asymmetric water vapour $\mathrm{H}_{2} \mathrm{O}^{*}$ for different seasons similar to Fig. 2.1 , but at $60^{\circ} \mathrm{S}$; (a) spring (SON: September-October-November), (b) summer (DJF: December-January-February), (c) autumn (MAM: March-April-May) and (d) winter (JJA: June-July-August); contour interval: $0.1 \mathrm{ppmv}$ (red colours refer to maximum positive values, blue colours refer to minimum negative values). 

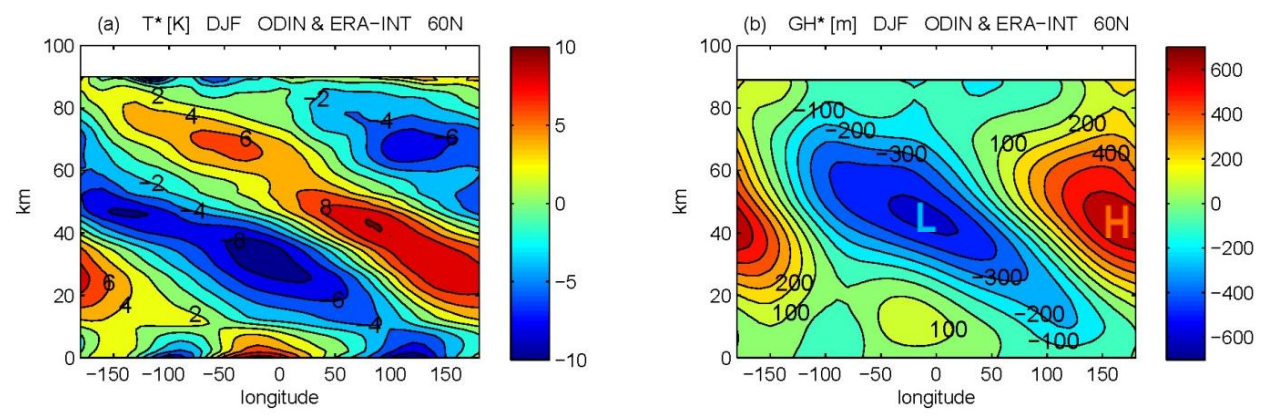

(c) $v_{g}^{*}[\mathrm{~m} / \mathrm{s}]$ DJF ODIN \& ERA-INT $60 \mathrm{~N}$
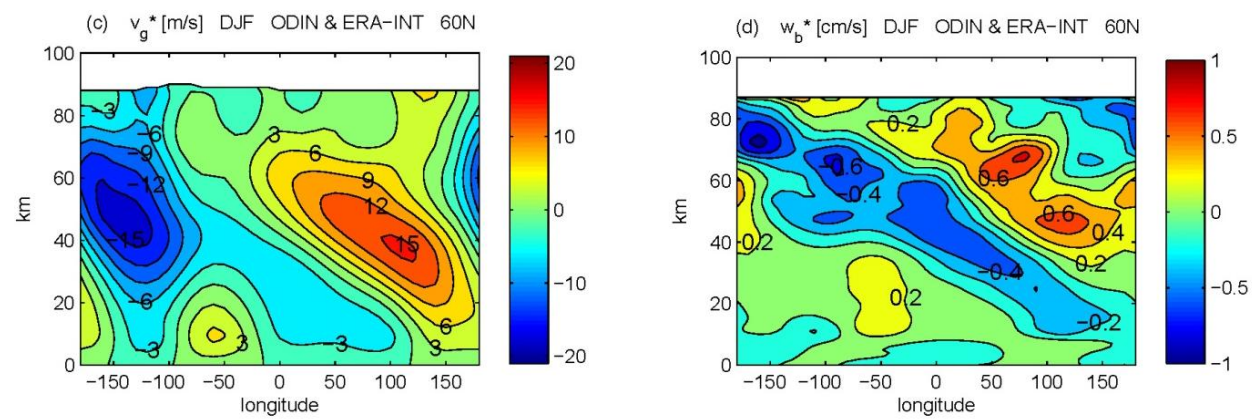

Fig. 3.1. Long-term means of zonally asymmetric components of (a) temperature $T^{*}$ (isolines in K), (b) geopotential height $\Phi^{*}$ (isolines in $\mathrm{m}$, in the picture denoted as $\left.\mathrm{GH}^{*}\right)$, (c) meridional geostrophic wind $v_{\mathrm{g}}^{*}$ (isolines in $\mathrm{ms}^{-1}$ ) and (d) geostrophically-balanced vertical wind $w_{\mathrm{b}}^{*}$ (isolines in $\mathrm{cm} \mathrm{s}^{-1}$ ) at $60^{\circ} \mathrm{N}$ for northern winter (DJF) of the time period 2001-2010, derived from combined Odin satellite data (50-100 km) and ERA Interim data $(0-50 \mathrm{~km})$ (red colours refer to maximum positive values, blue colours refer to minimum negative values).

In the Southern Hemisphere, a wave one pattern in $\mathrm{H}_{2} \mathrm{O}^{*}$ develops mainly during southern spring (Fig. 2.2a, SON), similarly to $\mathrm{O}_{3}^{*}$. Less pronounced stationary wave patterns in $\mathrm{H}_{2} \mathrm{O}$ with largest amplitudes of $0.1 \mathrm{ppm}$ (parts per million) are found also for northern summer (JJA) and southern summer (DJF), mainly in the mesosphere. These patterns might be due to zonal asymmetries in gravity wave breaking, e.g., in connection with gravity wave generation due to orography or due to storm tracks over the ocean basins. However, because the wave patterns of both $\mathrm{O}_{3}^{*}$ and $\mathrm{H}_{2} \mathrm{O}^{*}$ are weak during summer they are not discussed in this paper.

\subsection{Zonal asymmetries in $T^{*}$ and geostrophically balanced dynamics}

Figure 3.1 shows the zonally asymmetric temperature $T^{*}=T-[T]$ at $60^{\circ} \mathrm{N}$ during winter (here the brackets [ ] denote the zonal mean and the star * the deviation from the zonal mean), together with the zonally asymmetric components in geopotential height $\Phi^{*}$, geostrophic meridional wind $v_{\mathrm{g}}$ and quasi-geostrophically balanced vertical wind $w_{\mathrm{b}}^{*}$ derived as described in the following.

Firstly we derive the geopotential $\phi$ from temperature $T$ via the hydrostatic equation in terms of geopotential $(R$ is the ideal gas constant for dry air and $H=7500 \mathrm{~m}$ ):

$\frac{\partial \phi}{\partial z}=-\frac{R T}{H}$
Equation (1) is vertically integrated assuming $\phi=0$ for the standard pressure level $1000 \mathrm{hPa}$ as lower boundary, and the geopotential height is then determined by $\Phi=\phi / g$ ( $g$ : gravity acceleration of the earth). From geopotential $\phi$ we derive the zonal and meridional geostrophic winds $u_{\mathrm{g}}$ and $v_{\mathrm{g}}$ (here $f$ is Coriolis parameter, and $\partial / \partial x$ and $\partial / \partial y$ are used to denote the partial derivatives $(\operatorname{rcos} \varphi)^{-1} \partial / \partial \lambda$ and $r^{-1} \partial / \partial \varphi$ where $\lambda$ is longitude and $\varphi$ is latitude, based on the equidistant $10^{\circ} \times 10^{\circ}$ grid in longitude and latitude as described in Sect. 2.1):

$u_{\mathrm{g}}=-\frac{1}{f} \frac{\partial \phi}{\partial y}, v_{\mathrm{g}}=\frac{1}{f} \frac{\partial \phi}{\partial x}$

Note here that the longitudinal gradient becomes zero when averaging over the longitude, i.e. $\left[v_{\mathrm{g}}\right]=0$ and $v_{\mathrm{g}}^{*}=v_{\mathrm{g}}$.

For the derivation of $w_{\mathrm{b}}^{*}$ we introduce the separation in zonal mean and zonally asymmetric components into the quasi-geostrophically balanced equation for potential temperature $d_{\mathrm{g}} \theta+w\left(\theta_{0}\right)_{z}=Q(\theta$ is potential temperature, $d_{\mathrm{g}}=\partial_{t}+\mathbf{v}_{\mathrm{g}} \nabla, \partial_{t}$ is the local time derivative, $\nabla$ is the horizontal gradient, $\mathbf{v}_{\mathrm{g}}=\left(u_{\mathrm{g}}, v_{\mathrm{g}}\right), \theta_{0}=\theta_{0}(z)$ is a global mean potential temperature, $Q$ is the heating rate, and subscript $z$ denotes the derivative with respect to height). After removing the zonal mean part of the tendency we obtain an estimate for $w_{\mathrm{b}}^{*}$ for steady-state conditions $\left(\partial_{t} \theta=0\right)$ :

$w_{\mathrm{b}}^{*}=\left(Q^{*}-\left[u_{\mathrm{g}}\right] \frac{\partial \theta^{*}}{\partial x}-v_{\mathrm{g}^{*}} \frac{\partial[\theta]}{\partial y}-D^{*}\right) / \frac{\partial \theta_{0}}{\partial z}$ 

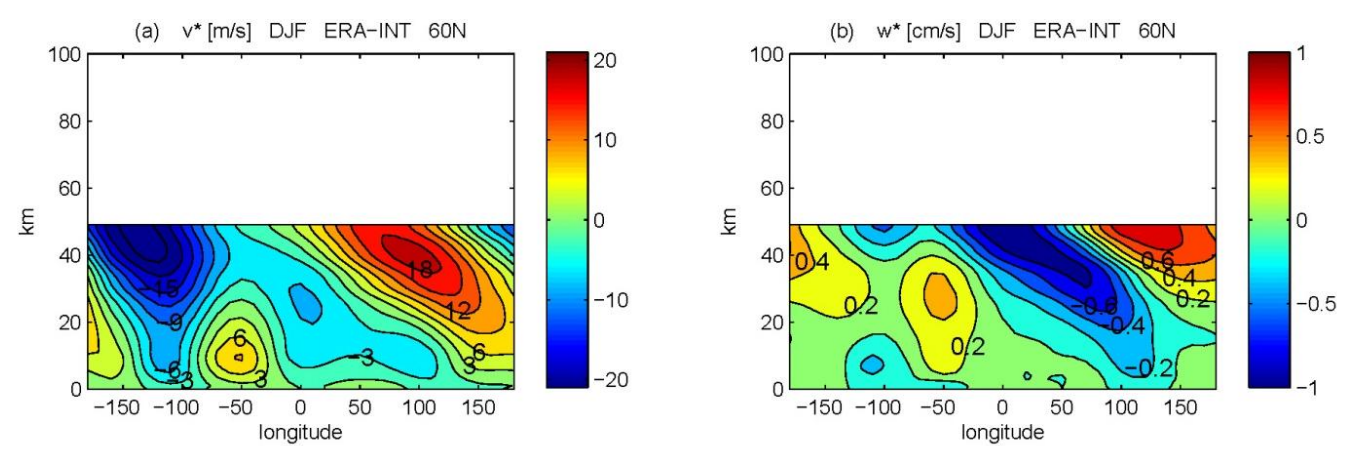

Fig. 3.2. Long-term means of (a) meridional wind $v^{*}$ (isolines in $\mathrm{m} \mathrm{s}^{-1}$ ) and (b) zonally asymmetric component of vertical wind $\mathrm{w}^{*}$ (isolines in $\mathrm{cms}^{-1}$ ) at $60^{\circ} \mathrm{N}$ for northern winter (DJF) of the time period 2001-2010, derived from ERA Interim (red colours refer to maximum positive values, blue colours refer to minimum negative values).

$\left(Q^{*}\right.$ is the zonally asymmetric heating rate and $D^{*}=\left(u_{\mathrm{g}}^{*} \theta^{*}\right)_{\mathrm{x}}+\left(v_{\mathrm{g}}^{*} \theta^{*}\right)_{y}-\left[v_{\mathrm{g}}^{*} \theta^{*}\right]_{y}$ denotes the zonally asymmetric component of eddy fluxes; the derivatives of the zonal mean values with respect to longitude are zero, i.e. $u_{\mathrm{g}}^{*}[\theta]_{x}=0 ; \quad\left[v_{\mathrm{g}}\right] \theta_{x}^{*}=\left[f^{-1} \phi_{x}\right] \theta_{x}^{*}=0 ; \quad\left[u_{\mathrm{g}}^{*} \theta^{*}\right]_{x}=0$; the subscripts $t, x, y$ and $z$ denote the derivatives with time, longitude, latitude and height). Note here that $D^{*}$ turns out to be smaller than the other advection terms by more than one order of magnitude, which might be an underestimation because it is derived only based on the zonal wave perturbations of the long-term stationary means. Note also that we include a small damping term $Q^{*}=-\alpha \theta^{*}$ ( $\alpha=1 / \tau, \tau$ : damping time, with $\tau=10$ days in troposphere, $\tau=7$ days in stratosphere, and then increasing with height to $\tau=10$ days in upper mesosphere), which affects the derived wave one pattern in $w_{\mathrm{b}}^{*}$ shown below (Fig. 3.1d) locally only up to $10 \%$. Here we do not consider explicitly the feedback of $\mathrm{O}_{3}^{*}$ on the zonally asymmetric radiative forcing $Q^{*}$ when deriving $w_{\mathrm{b}}^{*}$, although it may have an additional influence on the amplitude and phase of the wave one pattern of the order of $10-20 \%$, as suggested by several model studies (e.g., Gabriel et al., 2007; Gillett et al., 2009). However, for a first-order approximation of mean transport characteristics this approach seems to be acceptable because the contribution of the feedback of $Q^{*}$ to the amplitude of $\mathrm{O}_{3}^{*}$ is approximately one order of magnitude weaker than the observed amplitude in $\mathrm{O}_{3}^{*}$.

At $60^{\circ} \mathrm{N}$, the westward shift in phase in the wave one pattern of $T^{*}$ (Fig. 3.1a) corresponds to a westward shift in the wave one pattern of geopotential height anomaly $\Phi^{*}$ (Fig. 3.1b). The minimum in $\Phi^{*}$ at $40 \mathrm{~km}$ is found over the North Atlantic/Europe (the polar low anomaly in relation to the centre of the polar vortex) and the maximum in $\Phi^{*}$ over the Aleutians (the so-called Aleutian high anomaly). Consequently there are zonally asymmetric wave one patterns in the geostrophically balanced meridional and vertical winds (Fig. 3.1c, d), with poleward winds at the eastern flank of the polar low anomaly and equatorward winds at the west- ern flank of the polar low anomaly, indicating strong zonal asymmetries in meridional tracer transport. Note here again that - as for $\mathrm{H}_{2} \mathrm{O}^{*}$ - the matching procedures for $T^{*}$ at around $50 \mathrm{~km}$ do not have a substantial influence on the vertical structure of the wave pattern in $T^{*}$ (see Appendix A for comparison with the field $T^{*}$ at $60^{\circ} \mathrm{N}$ without applying the matching procedure).

The geostrophically approximated winds are usually weaker than the non-geostrophically approximated winds, in particular the vertical wind component. For comparison, Fig. 3.2 shows the corresponding fields $v^{*}$ and $w^{*}$ retrieved directly from the ERA Interim data, indicating that the amplitudes of the wave one pattern differ in $v^{*}$ by about $30 \%$ and for $w^{*}$ by about $50 \%$. However, the spatial structure and the westward shift in phase with increasing height are fairly well captured by the approach. On the other hand, the $w^{*}$-field derived from ERA Interim includes uncertainties because of the lack in observations of vertical winds and because of the general problems of middle atmospheric data assimilation. For example, the restriction of the assimilation model to levels somewhat above stratopause altitudes could prohibit vertical wave propagation and could lead, subsequently, to an incorrect description of the wave one amplitudes in the upper stratosphere (Polavarapu et al., 2005). Thus, for the linear solutions of the transport equation discussed in Sect. 3 we use $v_{\mathrm{g}}^{*}$ and $w_{\mathrm{b}}^{*}$ as a first guess of homogeneously derived wind components for the whole middle atmosphere, keeping in mind the uncertainties in $w_{\mathrm{b}}^{*}$ when interpreting the results.

A similar wave one pattern is found in the Southern Hemisphere at $60^{\circ} \mathrm{S}$ during autumn, but with weaker amplitude (Fig. 3.3). A westward shift in phase of $T^{*}$ (Fig. 3.3a) corresponds to a westward shift in geopotential height anomaly $\Phi^{*}$ (Fig. 3.3b), with a southern polar low anomaly centred at around $30^{\circ} \mathrm{W}$ and a high anomaly centred at around $150^{\circ} \mathrm{E}$ at altitudes of $\sim 40 \mathrm{~km}$. As in northern winter, there are poleward winds at the eastern flank of the southern polar low anomaly and equatorward winds at the western flank of the southern polar low anomaly (note here the reversed 

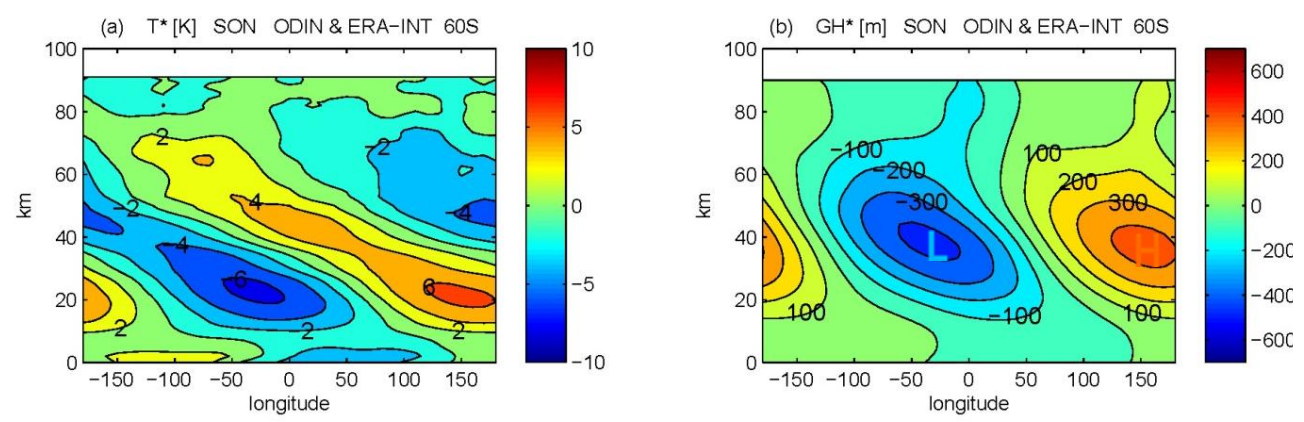

(c) $v_{g}^{*}[\mathrm{~m} / \mathrm{s}]$ SON ODIN \& ERA-INT $60 \mathrm{~S}$

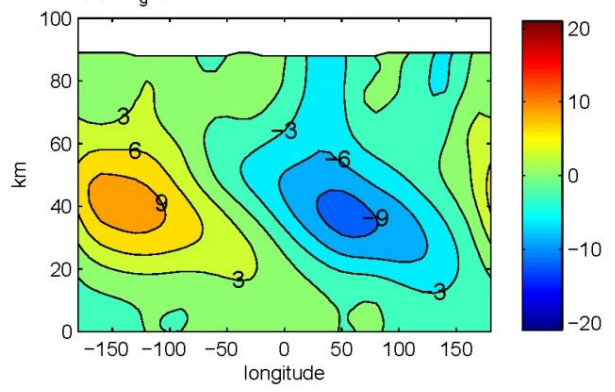

(d) $w_{b}^{*}[\mathrm{~cm} / \mathrm{s}]$ SON ODIN \& ERA-INT $60 \mathrm{~S}$

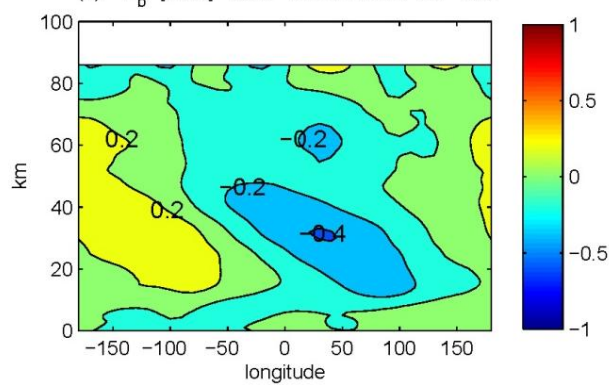

Fig. 3.3. Long-term means of $T^{*}, \Phi^{*}, v_{\mathrm{g}}^{*}$ and $w_{\mathrm{b}}^{*}$ as in Fig. 3.1, but at $60^{\circ} \mathrm{S}$ for southern spring (SON) (red colours refer to maximum positive values, blue colours refer to minimum negative values).

sign of Coriolis force), which also indicate strong zonal asymmetries in meridional tracer transport. The similarity in phase of the northern and the southern wave one pattern might be due to similarities in planetary-scale orography (e.g., the north-southward direction of Rocky Mountains/Andes mountain ridge extending over both northern and Southern Hemisphere) or due to similarities in the differences in tropospheric wave activity over the Pacific and over the Atlantic/Indian ocean basins.

In Sect. 3 we analyse the effect of $v_{\mathrm{g}}^{*}$ and $w_{\mathrm{b}}^{*}$ on the stationary wave patterns in $\mathrm{O}_{3}^{*}$ and $\mathrm{H}_{2} \mathrm{O}^{*}$ based on a simplified tracer transport equation. Note here that we derived also other non-geostrophic wind components via the Phillips approximation $\left(u_{\mathrm{ag}}=\left(d_{\mathrm{g}} v_{\mathrm{g}}\right) / f\right.$ and $v_{\mathrm{ag}}=\left(d_{\mathrm{g}} u_{\mathrm{g}}\right) / f$ with steady state conditions $\partial_{t}=0$ and $|f|>0$ for the extra-tropics), and residual winds via $f v_{\text {res }}=\left[v_{\mathrm{g}}^{*} q_{\mathrm{g}}^{*}\right]$ from quasi-geostrophic potential vorticity fluxes (with $q_{\mathrm{g}}=f-u_{\mathrm{g} y}+v_{\mathrm{g} x}+f\left(\theta^{*} / \theta_{0 z}\right)_{z}$ and $\left.\left(v_{\text {res }}\right)_{y}+\left(w_{\text {res }}\right)_{z}=0\right)$. However, the effect of these ageostrophic components on the stationary wave patterns in $\mathrm{O}_{3}^{*}$ and $\mathrm{H}_{2} \mathrm{O}^{*}$ turns out to be at least one order of magnitude smaller than those of $v_{\mathrm{g}}^{*}$ and $w_{\mathrm{b}}^{*}$ and are not considered here. A shortcoming is, of course, that the ageostrophic and residual winds were only derived from the stationary flow pattern, because the derivation of transient flow patterns is restricted due to the temporal and spatial resolution of the Odin data. Furthermore, the impact of gravity waves on the residual circulation is not included. Nevertheless, based on the linear approach for the transport equation discussed in Sect. 3 we expect to extract the first-order approximation of the processes determining the stationary wave patterns in $\mathrm{O}_{3}^{*}$ and $\mathrm{H}_{2} \mathrm{O}^{*}$ when analyzing the effects of the stationary quasigeostrophically-balanced flow on $\mathrm{O}_{3}^{*}$ and $\mathrm{H}_{2} \mathrm{O}^{*}$.

\section{Simplified transport equation for zonally asymmetric tracer components}

\subsection{Transport tendencies and linear chemical loss rates}

Based on the transport equation for a tracer $\mu$ :

$\frac{d \mu}{d t}=\frac{\partial \mu}{\partial t}+\mathbf{v} \nabla \mu=S$

$(\mathbf{v}=(u, v, w), S:$ chemical sources), the derived winds are used to estimate the transport tendencies for the zonally asymmetric component $\mu^{*}=\mu[\mu]$ :

$\frac{\partial \mu^{*}}{\partial t}+[\mathbf{v}] \nabla \mu^{*}=S^{*}+G^{*}-D^{*}$

with a generation term $G^{*}=-v^{*}[\mu]_{y}-w^{*}[\mu]_{z}$, a zonally asymmetric component of the eddy fluxes

$D^{*}=D-[D]=\left(u^{*} \mu^{*}\right)_{x}+\left(v^{*} \mu^{*}\right)_{y}+\left(w^{*} \mu^{*}\right)_{z}-\left[v^{*} \mu^{*}\right]_{y}-$

$\left[w^{*} \mu^{*}\right]_{z}$, and a chemical source term $S^{*}=S-[S]$. The generation term $G^{*}$ gives a contribution to the tendency of $\mu^{*}$ as a function of the zonal mean tracer distribution $[\mu]$ and the zonal asymmetries in meridional and vertical winds $v^{*}$ and $w^{*}$. Applying our approximation of the winds from Sect. 2.3, we find that $G_{\mathrm{g}}^{*}=-v_{\mathrm{g}}^{*}[\mu]_{y}-w_{\mathrm{b}}^{*}[\mu]_{z}$ is stronger than the eddy flux term $D^{*}$ by approximately one order for 
Table 2. Prescribed lifetime $\tau$ and sensitivity parameter $\gamma$ to parameterize the mean chemical loss of zonally asymmetric ozone and the sensitivity of non-linear interactions between wave perturbations in ozone photochemistry and temperature; the lifetime is prescribed according to Brasseur and Solomon (1995) and the sensitivity parameter according to Froidevaux et al. (1989) and Ward et al. (2010); both parameters are slightly adjusted for the solutions of the transport equation at high mid-latitudes (details see Sect. 3); note that the logarithmic decrease of $\gamma$ below $35 \mathrm{~km}$ and above $55 \mathrm{~km}$ is prescribed artificially to ensure a smoothed transition between the levels.

\begin{tabular}{lcccccccccc}
\hline Height $[\mathrm{km}]$ & 20 & 25 & 30 & 35 & 40 & 45 & 50 & 55 & 60 & 65 \\
\hline Lifetime $\tau[\mathrm{s}]$ & $2 \times 10^{7}$ & $5 \times 10^{6}$ & $8 \times 10^{5}$ & $9 \times 10^{4}$ & $4 \times 10^{4}$ & $2 \times 10^{4}$ & $1 \times 10^{4}$ & $9 \times 10^{3}$ & $9 \times 10^{3}$ & $9 \times 10^{3}$ \\
Sensitivity $\gamma[\mathrm{K}]$ & 100 & 200 & 400 & 800 & 1500 & 1200 & 1000 & 500 & 250 & 125 \\
\hline
\end{tabular}

both $\mathrm{O}_{3}$ and $\mathrm{H}_{2} \mathrm{O}$. As in case of the eddy heat fluxes, D* might be somewhat underestimated because it is derived only based on the long-term mean of the stationary wave patterns, whereas transient eddies cannot be derived from the used data alone.

Also the zonally asymmetric source term $S^{*}=S-[S] \approx$ $P^{*}-L^{*}[\mu]-[L] \mu^{*}$ cannot be derived from the data alone $\left(P^{*}=P-[P]\right.$ denotes the zonally asymmetric chemical production and $L^{*}=L-[L]$ the zonally asymmetric loss rate; second order terms $L^{*} \mu^{*}$ are neglected in the following discussion), because a detailed assessment of the effects of temperature-dependent stratospheric ozone chemistry on the stationary wave patterns requires extensive calculations of photolysis rates and highly non-linear catalytic ozone destruction cycles, e.g., the $\mathrm{NO}_{x^{-}}, \mathrm{HO}_{\mathrm{x}^{-}}, \mathrm{ClO}_{\mathrm{x}^{-}}$and $\mathrm{BrO}_{\mathrm{x}}$ cycles, which need more information of the involved species with higher resolution in time and space than provided by satellite data. However, in order to give a first estimation of these effects we include linear parameterizations of the chemical sources as described in the following.

As a first step we use some important temperaturedependent reaction rates for a simplified first-guess parameterization of the loss rate $L^{*}(T)$ indicating the linear response of the chemistry to temperature perturbations via the loss term $L^{*}(T) \cdot[\mu]$. Two of the most important reactions involved in stratospheric ozone chemistry are the reactions $\mathrm{O}_{3}+\mathrm{O}^{3} \mathrm{P} \rightarrow 2 \mathrm{O}_{2}$ and $\mathrm{O}_{3}+\mathrm{NO} \rightarrow \mathrm{O}_{2}+\mathrm{NO}_{2}$ (Brasseur and Solomon, 1995), which we combine to compute the mean loss rate $L_{\mathrm{O}_{3}}(T)=k_{1}\left[\mathrm{O}^{3} \mathrm{P}\right]+0.5 \cdot k_{2}[\mathrm{NO}]$ (where $k_{1}=8.0 \times 10^{-12} \exp (-2060 / T) \mathrm{cm}^{3} \mathrm{~s}^{-1}$ and $k_{2}=$ $1.8 \times 10^{-12} \exp (-1370 / T) \mathrm{cm}^{3} \mathrm{~s}^{-1} ; T$ : temperature in K). Here we simply prescribe a mean profile of $\mathrm{O}^{3} \mathrm{P}$ adopted from Brasseur and Solomon (1995), and an approximated mean profile of $\mathrm{NO}$ mixing ratio at $60^{\circ} \mathrm{N}$ according to Visconti and Pitari (1987) in combination with a reduced reaction coefficient for the calculation of the long-term means $\left(0.5 \cdot k_{2}\right.$ instead of $\left.k_{2}\right)$ because of the strong diurnal cycle of NO.

In the upper stratosphere and mesosphere, ozone is primarily controlled by temperature-dependent photochemistry and the lifetime decreases rapidly with height. Therefore, as a second step, we introduce a parameterization of the effects of non-linear interactions between complex photochemistry and temperature in terms of a sensitivity parameter $\gamma$ according to the estimations of Froidevaux et al. (1989), Brasseur and Solomon (1985) and Ward et al. (2010), which is described in detail in Sect. 3.2 when discussing the contributions of the individual tendencies to the observed wave pattern. In the mesosphere, there is a pronounced diurnal cycle, but a possible effect of the diurnal cycle on the long-term means of the stationary wave patterns is not considered here, because the largest amplitudes in $\mathrm{O}_{3}^{*}$ are found in the stratosphere. Additionally, we calculate the tendencies due to the linear feedback of ozone chemistry via the loss term $[L] \mu^{*}$ based on a height-dependent loss rate $[L]=1 / \tau$, which is prescribed by a photochemical lifetime $\tau$ according to the estimations of Brasseur and Solomon (1995), as given in Table 2.

The chemical loss rates of $\mathrm{H}_{2} \mathrm{O}$ are weak in the whole middle atmosphere, and, therefore, it is an excellent tracer for transport studies in both the stratosphere and the mesosphere (Brasseur and Solomon, 1995). The most important chemical processes influencing middle atmospheric $\mathrm{H}_{2} \mathrm{O}$ concentrations are methane oxidation $\mathrm{CH}_{4}+\mathrm{OH} \rightarrow \mathrm{CH}_{3}+\mathrm{H}_{2} \mathrm{O}$ and loss of $\mathrm{H}_{2} \mathrm{O}$ via the reaction $\mathrm{H}_{2} \mathrm{O}+\mathrm{O}^{1} \mathrm{D} \rightarrow 2 \mathrm{OH}$ (Brasseur and Solomon, 1995), with corresponding source terms $P^{*}=k_{3}$ $\left[\mathrm{CH}_{4}\right][\mathrm{OH}]$ and $L^{*}\left(\mathrm{H}_{2} \mathrm{O}\right)=k_{4}\left[\mathrm{O}^{1} \mathrm{D}\right]\left(k_{3}=2.4 \times 10^{-12} \exp (-\right.$ $1710 / T) \mathrm{cm}^{6} \mathrm{~s}^{-1}$ and $k_{4}=2.2 \times 10^{-12} \mathrm{~cm}^{3} \mathrm{~s}^{-1} ; T$ : temperature in $\mathrm{K}$ ). The reaction coefficients and the mean profiles of $\mathrm{CH}_{4}, \mathrm{OH}$ and $\mathrm{O}^{1} \mathrm{D}$ for mid-latitudes are adopted from Brasseur and Solomon (1995). Again, the photolysis rates are not considered here and we assume that the effects on the chemical species are - to first order - zonally symmetric when averaging over long time periods. In particular, we do not consider the photolysis of $\mathrm{H}_{2} \mathrm{O}$ by absorption of the Lyman- $\alpha$ line, which reduces the $\mathrm{H}_{2} \mathrm{O}$ concentrations in the upper mesosphere and lower thermosphere (Brasseur and Solomon, 1995), because the strongest amplitudes in the long-term means of $\mathrm{H}_{2} \mathrm{O}^{*}$ are observed below $80 \mathrm{~km}$. The photochemical lifetime of $\mathrm{H}_{2} \mathrm{O}$ slowly decreases with height which is responsible for the decrease of zonal mean $\mathrm{H}_{2} \mathrm{O}$ with increasing height in the mesosphere. However, we neglect the feedback of photochemistry to the stationary wave pattern via the loss term $[L] \cdot \mathrm{H}_{2} \mathrm{O}^{*}$ because of the long photochemical lifetime of $\mathrm{H}_{2} \mathrm{O}$ below $80 \mathrm{~km}$ in comparison to the transport time scales, as discussed in detail below when comparing the tendencies for $\mathrm{O}_{3}^{*}$ and $\mathrm{H}_{2} \mathrm{O}^{*}$. 

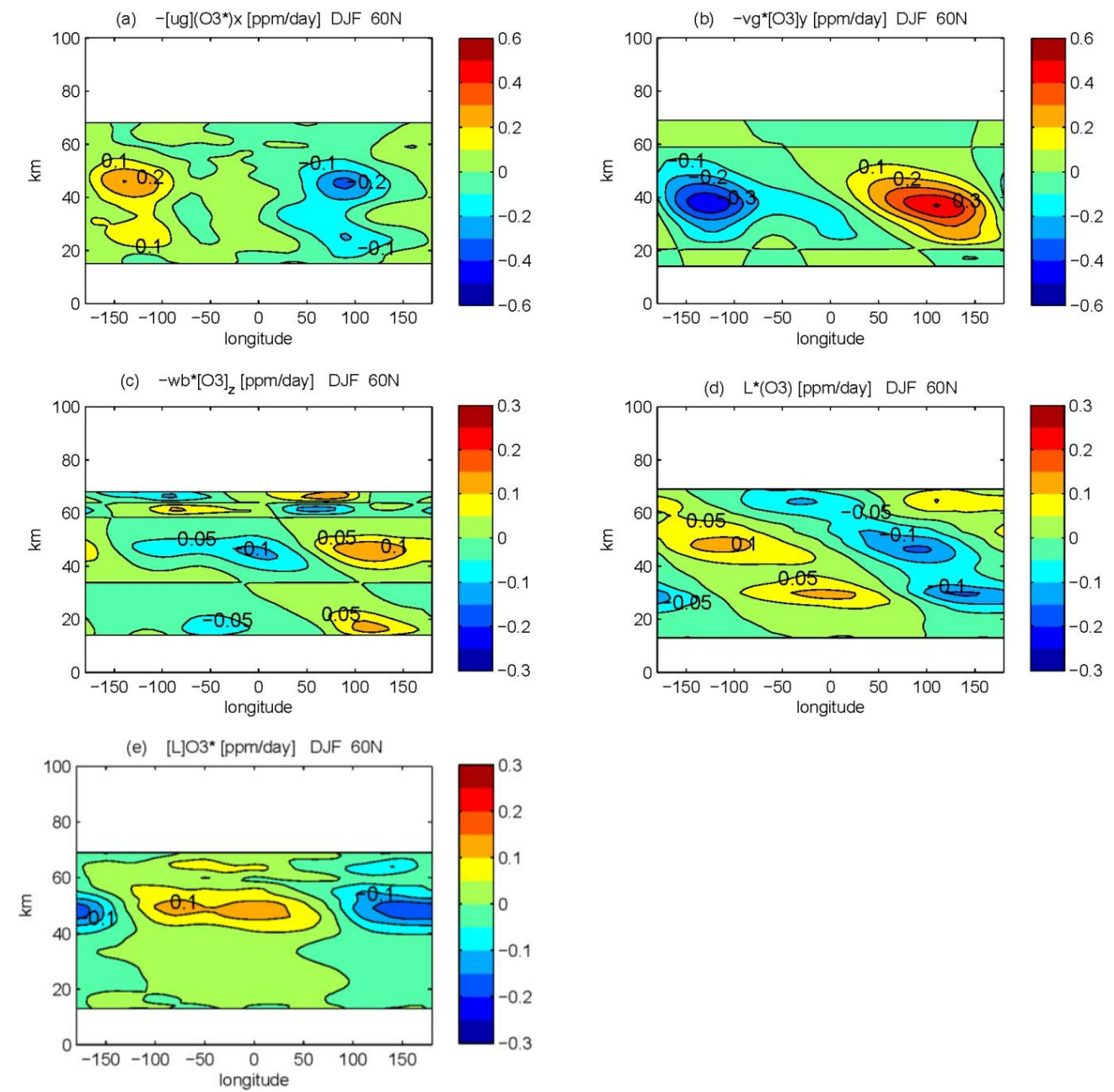

Fig. 4.1. (a-d): Mean tendencies for zonally asymmetric ozone $\mathrm{O}_{3}^{*}$ at $60^{\circ} \mathrm{N}$ during winter (DJF) of the time period 2001-2010; (a) $-\left[u_{\mathrm{g}}\right]$ $\left(\mathrm{O}_{3}^{*}\right)_{x},(\mathbf{b})-v_{\mathrm{g}}^{*}\left[\mathrm{O}_{3}\right]_{y},(\mathbf{c})-w^{*}\left[\mathrm{O}_{3}\right]_{z}$, as derived from mean ozone and mean geostrophically-balanced winds, and (d) zonally asymmetric chemical loss rate $L^{*}\left(\mathrm{O}_{3}\right)=-L^{*}(T) \cdot\left[\mathrm{O}_{3}\right]$ as derived from zonal mean ozone and temperature-dependent reaction rates of ozone depletion by atomic oxygen and nitric oxide (details see Sect. 3.1); contour interval for (a) and (b): $0.1 \mathrm{ppmv}^{-1} \mathrm{yy}^{-1}$, and for (c) and (d): $0.05 \mathrm{ppmv}^{-1}$ day $^{-1}$. (e): Mean loss term $[L] \cdot \mathrm{O}_{3}^{*}$ at $60^{\circ} \mathrm{N}$ during winter (DJF) as a function of a prescribed mean loss rate $[L]$ (see Table 2 ) and the observed $\mathrm{O}_{3}^{*}$ shown in Fig. 1.1b; contour interval: $0.05 \mathrm{ppmv}^{-1} \mathrm{y}^{-1}$ (red colours refer to maximum positive values, blue colours refer to minimum negative values).

For illustration, Fig. 4.1 shows the individual tendencies for $\mathrm{O}_{3}^{*}$ at $60^{\circ} \mathrm{N}$. When comparing Fig. $4.1 \mathrm{~b}$ with Fig. 3.1c, and considering a meridional gradient of zonal mean ozone $\left[\mathrm{O}_{3}\right]_{y}<0$ in middle and upper stratosphere, we find positive tendencies $-v_{\mathrm{g}}\left[\mathrm{O}_{3}\right]_{y}$ at these levels in regions of poleward winds at the eastern flank of polar low anomaly and negative tendencies in regions of southward winds at the western flank of polar low anomaly. These tendencies are - to first order - balanced by the advection of the perturbation within the zonal mean westerlies, $-\left[u_{\mathrm{g}}\right]\left(\mathrm{O}_{3}^{*}\right)_{x}$, depicted in Fig. 4.1a. The vertical structure of the wave pattern in $-w_{\mathrm{b}}^{*}\left[\mathrm{O}_{3}\right]_{z}$ shows a shift in phase between lower and upper stratospheric altitudes (Fig. 4.1c). This feature becomes evident when considering that the vertical gradient of zonal mean ozone $\left[\mathrm{O}_{3}\right]_{z}$ changes its sign at about $35 \mathrm{~km}$, i.e. it is related to the wave pattern in $w_{\mathrm{b}}^{*}$ shown in Fig. 3.1d but with different sign below and above $\sim 35 \mathrm{~km}$. The tendency $-w_{\mathrm{b}}^{*}\left[\mathrm{O}_{3}\right]_{z}$ is weaker than the horizontal tendencies, but its strength may be somewhat underestimated because of the underlying quasigeostrophic approximation. In addition, the chemical loss term $L^{*}\left(\mathrm{O}_{3}\right)=-L^{*}(T) \cdot\left[\mathrm{O}_{3}\right]$ (Fig. 4.1d) indicates a significant contribution to the tendency budget, but it is also slightly weaker than the horizontal tendencies. Here we only note that the chemical loss rates at around $30 \mathrm{~km}$ are mainly related to the layer of enhanced NO concentrations at these altitudes (via the loss rate $-k_{2}[\mathrm{NO}]$ ), and those in the upper stratosphere are mainly related to the temperature-dependent loss due to reaction with atomic oxygen (via $\left.-k_{1}\left[\mathrm{O}^{3} \mathrm{P}\right]\right)$. 

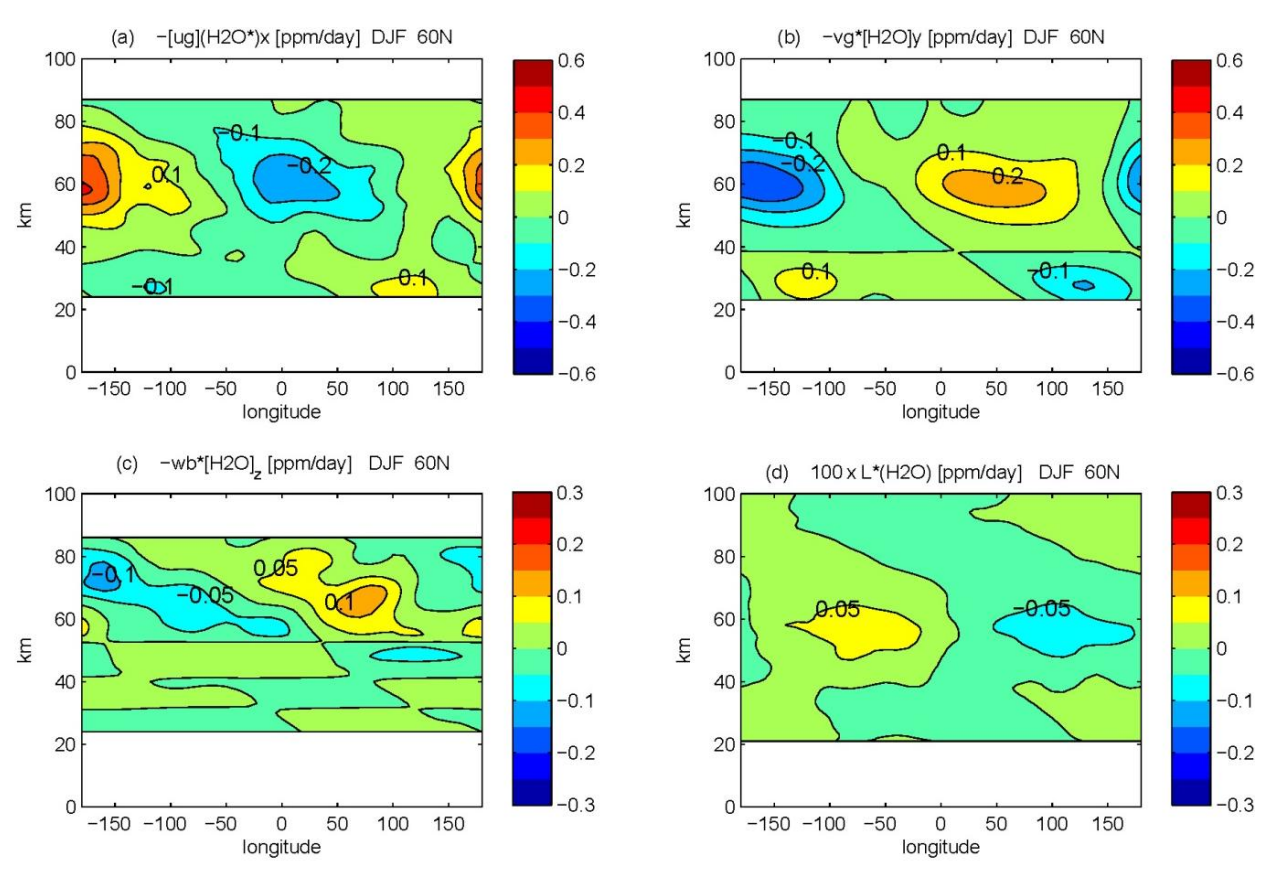

Fig. 4.2. Mean tendencies of zonally asymmetric water vapour $\mathrm{H}_{2} \mathrm{O}^{*}$ at $60^{\circ} \mathrm{N}$ during winter (DJF) of the time period 2001-2010; (a) $-\left[u_{\mathrm{g}}\right]\left(\mathrm{H}_{2} \mathrm{O}^{*}\right)_{x},(\mathbf{b})-v_{\mathrm{g}}^{*}\left[\mathrm{H}_{2} \mathrm{O}\right]_{y},(\mathbf{c})-w^{*}\left[\mathrm{H}_{2} \mathrm{O}\right]_{z}$ and (d) linear zonally asymmetric loss rate $L^{*}\left(\mathrm{H}_{2} \mathrm{O}\right)=-L^{*}(T)\left[\mathrm{H}_{2} \mathrm{O}\right]$ multiplied by a factor of 100, as derived from mean ozone and mean geostrophically-balanced winds (details see Sect. 3.1); contour interval for (a) and (b): $0.1 \mathrm{ppmv}^{-1} \mathrm{yy}^{-1}$, and for (c) and (d): $0.05 \mathrm{ppmv}_{\text {day }}{ }^{-1}$ (red colours refer to maximum positive values, blue colours refer to minimum negative values).

In addition to Fig. 4.1a-d, which indicate processes producing the stationary wave pattern in ozone, Figure 4.1e shows the linear feedback of $\mathrm{O}_{3}^{*}$ to the configuration of the wave pattern via the loss term $[L] \cdot \mathrm{O}_{3}^{*}$ as derived for the observed field $\mathrm{O}_{3}^{*}$. The effect of $[L] \cdot \mathrm{O}_{3}^{*}$ is most pronounced at upper stratospheric altitudes where $[L]=1 / \tau$ becomes large and where the amplitude of the stationary wave one pattern in $\mathrm{O}_{3}^{*}$ is still significant. Therefore, this tendency contributes substantially to the structure of the upper stratospheric part of the wave one pattern in $\mathrm{O}_{3}^{*}$, which becomes clearer below when discussing the solution of the simplified transport equation in Sect. 3.2.

Figure 4.2 illustrates the individual tendencies for $\mathrm{H}_{2} \mathrm{O}^{*}$ at $60^{\circ} \mathrm{N}$ during winter. The jump in phase of the meridional advection $-v_{\mathrm{g}}\left[\mathrm{H}_{2} \mathrm{O}\right]_{y}$ (Fig. 4.2b) and of the vertical advection $-w_{\mathrm{b}}^{*}\left[\mathrm{H}_{2} \mathrm{O}\right]_{z}$ (Fig. $4.2 \mathrm{c}$ ) in the upper stratosphere becomes evident when considering that the zonal mean concentrations of $\mathrm{H}_{2} \mathrm{O}$ at $60^{\circ} \mathrm{N}$ increase from about 2-3 ppm at lower stratosphere to about 6-7 ppm at upper stratosphere/lower mesosphere altitudes, but then decrease with height in the middle and upper mesosphere (e.g., Randel et al., 1998; Urban et al., 2007). Therefore, at $60^{\circ} \mathrm{N}$ during northern winter, the mean horizontal gradient $\left[\mathrm{H}_{2} \mathrm{O}\right]_{y}$ and vertical gradient $\left[\mathrm{H}_{2} \mathrm{O}\right]_{z}$ change in sign at upper stratosphere/lower mesosphere altitudes (i.e. $\left[\mathrm{H}_{2} \mathrm{O}\right]_{y}>0$ and $\left[\mathrm{H}_{2} \mathrm{O}\right]_{z}>0$ for $h<50 \mathrm{~km}$, while $\left[\mathrm{H}_{2} \mathrm{O}\right]_{y}<0$ and $\left[\mathrm{H}_{2} \mathrm{O}\right]_{z}<0$ for $h>50 \mathrm{~km}$ ), leading to the jump in phase at these altitudes if a wave one pattern in the zonally asymmetric wind components $v_{\mathrm{g}}^{*}$ and $w_{\mathrm{b}}^{*}$ shown in Fig. 3.1c, $\mathrm{d}$ is present. As for $\mathrm{O}_{3}^{*}$, the tendencies due to meridional advection $-v_{\mathrm{g}}\left[\mathrm{H}_{2} \mathrm{O}\right]_{y}$ are - to first order - balanced by the advection of the perturbation within the zonal mean westerlies, $-\left[u_{\mathrm{g}}\right]\left(\mathrm{H}_{2} \mathrm{O}^{*}\right)_{x}$, which is depicted in Fig. 4.2a. The tendencies of the vertical advection (Fig. 4.2c) are more pronounced in the mesosphere than in the stratosphere, but weaker than those of horizontal advection. The chemical loss rate $L^{*}\left(\mathrm{H}_{2} \mathrm{O}\right)=-L^{*}(T) \cdot\left[\mathrm{H}_{2} \mathrm{O}\right]$ (Fig. $4.2 \mathrm{~d}$ ) is very weak indicating the long chemical lifetime of $\mathrm{H}_{2} \mathrm{O}$ throughout the whole middle atmosphere. Here we only note that the temperature-dependent production due to methane oxidation is much weaker than the loss rate. For the estimation of the production of $\mathrm{H}_{2} \mathrm{O}$ due to methane oxidation we use a mean profile for $\mathrm{CH}_{4}$, and this production term might become more relevant if zonal asymmetries in the $\mathrm{CH}_{4}$ distribution are taken into account. However, this possibility is not examined in this paper. Note here that the zonally asymmetric chemical loss term $[L] \cdot \mathrm{H}_{2} \mathrm{O}^{*}$ increases with height in the mesosphere, but that it is very weak in comparison to the transport tendencies. For example, a photochemical lifetime of more than 10 days at $70-80 \mathrm{~km}$ (Brasseur and Solomon, 1995) leads to loss rates $[L] \cdot \mathrm{H}_{2} \mathrm{O}^{*}$ of less than $0.01-0.02 \mathrm{ppm} \mathrm{day}^{-1}$ at these altitudes, which is smaller than the zonally asymmetric transport tendencies by more than a factor of 10 . 
From the derivation of advection by ageostrophic winds from quasi-geostrophically balanced equations described in Sect. 2.3, we find that these terms are of secondary importance in comparison to the advection by zonal mean westerlies, i.e. $u_{a g} \mu_{x}^{*} \ll\left[\mathrm{u}_{\mathrm{g}}\right] \mu_{x}^{*}, v_{\mathrm{ag}} \mu_{y}^{*} \ll\left[u_{\mathrm{g}}\right] \mu_{x}^{*}$ and $w^{*} \mu_{z}^{*} \ll\left[u_{\mathrm{g}}\right] \mu_{x}^{*}$. As in the case of the temperature advection and eddy heat fluxes considered in Sect. 2, the influence of the non-balanced ageostrophic components on the tracer advection and the eddy tracer fluxes may be underestimated because they are derived based only on long-term mean stationary and quasi-geostrophically balanced wave components, neglecting interannual variations of the stationary components and transient waves. In the middle stratosphere, stationary waves may be usually larger than transient waves, but in the lower stratosphere transient wave activity contribute largely to the eddy transport processes (Gabriel and Schmitz, 2003; Haklander et al., 2008). Also, above the stratopause transient waves may become more important. However, in the framework of this paper the non-balanced ageostrophic components and the transient wave activity cannot be quantified because of the limitations in the temporal and spatial resolution of the Odin data.

\subsection{Contribution of the individual tendencies to the stationary wave patterns}

Now we assume that, to first order, the term $G_{\mathrm{g}}^{*}\left(\mu^{*}\right)$ of Eq. (5) is balanced by the advection of $\mu^{*}$ within the zonal mean westerlies $\left[u_{\mathrm{g}}\right]$, i.e. based on a first order approximation of the transport equation (assuming steady state with $\partial_{t} \mu=0$ and a zonally asymmetric loss term $\left.L \approx[L] \mu^{*}+L^{*}[\mu] \gg L^{*} \mu^{*}\right)$ we can formulate:

$$
\begin{aligned}
& \frac{d \mu^{*}}{d t} \approx\left[u_{\mathrm{g}}\right] \frac{\partial \mu^{*}}{\partial x} \approx G_{\mathrm{g}}^{*} t+S^{*} \\
& =-v_{\mathrm{g}} \frac{\partial[\mu]}{\partial y}-w^{*} \frac{\partial[\mu]}{\partial z}-L^{*}[\mu]-[L] \mu^{*}
\end{aligned}
$$

In a first step we focus on the linear processes producing the wave pattern in ozone and water vapour as a function of only transport and temperature, i.e. we use the linear loss terms $L^{*}(T)[\mu]$ shown in Figs. 4.1d and 4.2d whereas the effects via the non-linear interaction between photochemistry and temperature and via the loss term $[L] \mathrm{O}_{3}^{*}$ are examined in a second step below. We can derive a specific solution $\mu^{*}=\mu^{*}(T R)$ via Fourier decomposition of the left-hand and the right-hand side of the approximated equation $\mu_{x}^{*} \approx\left(G_{\mathrm{g}}^{*}+L^{*}[\mu]\right) /\left[u_{\mathrm{g}}\right]$ for zonal wave numbers $k$ (where $\mu_{x}^{*}=\partial \mu^{*} / \partial x$; note that $\left[u_{\mathrm{g}}\right]>0$ is usually fulfilled in the extra-tropics from the upper troposphere to the lower mesosphere except during summer months; here we use $1 /\left[u_{\mathrm{g}}\right] \approx\left[u_{\mathrm{g}}\right] /\left(\left[u_{\mathrm{g}}\right]^{2}+\varepsilon\right)$ with $\varepsilon=1 \mathrm{~m} \mathrm{~s}^{-1}$ to avoid unrealistic values). This gives:

$\mu_{x}^{*}=\Sigma i k c_{k} e^{i k x}$ with $\mu^{*}=\Sigma c_{k} e^{i k x}$

$\left(G_{\mathrm{g}}^{*}+L^{*}[\mu]\right) /\left[u_{\mathrm{g}}\right]=\Sigma C_{k} e^{i k x}$
Then the comparison of the resulting coefficients $\left(i k c_{k}=C_{k}\right)$ for each of the horizontal wave numbers $k$ provides an estimate $\mu^{*}(\mathrm{TR})$ as a function of $G_{\mathrm{g}}^{*}+L^{*}[\mu]$, and an estimate of the effects of the individual tendencies included in $G_{\mathrm{g}}^{*}$ or $L^{*}[\mu]$.

The resulting field $\mathrm{O}_{3}^{*}(T R)$ and the individual contributions of the tendencies at $60^{\circ} \mathrm{N}$ for northern winter are plotted in Fig. 5.1. The solution $\mathrm{O}_{3}^{*}(T R)$ (Fig. 5.1a) shows a wave one pattern similar to the observed $\mathrm{O}_{3}^{*}$ field shown in Fig. $1.1 \mathrm{~b}$, i.e. it captures the phase with minimum values over Northern Europe and maximum values over the Aleutians quite well, but it underestimates the amplitude and does not capture details like the observed double-peak structure of enhanced amplitudes in the lower and the upper stratosphere (compare Figs. 1.1b and 5.1a). Figure 5.1b demonstrates that the zonal asymmetries in the meridional advection are the primary source of the wave one pattern up to around $40 \mathrm{~km}$. The contributions of zonal asymmetries in the vertical advection (Fig. 5.1c) and of the chemical loss term $L^{*}\left(\mathrm{O}_{3}\right)=-L^{*}(T) \cdot\left[\mathrm{O}_{3}\right]$ (Fig. 5.1d) are weaker; however, the inclusion in the solution $\mathrm{O}_{3}^{*}(T R)$ leads locally to an improvement of the spatial structure in comparison to the observed wave pattern. In particular, the double peak pattern due to vertical advection with enhanced amplitude in the lower and in the upper stratosphere and the contribution of the chemical loss term located mainly at $20-30 \mathrm{~km}$ altitude (which is counteracting the effect of meridional advection at these altitudes) lead to a slight disruption in the wave pattern and a more pronounced part of the wave pattern in the lower and in the upper stratosphere. However, there are still strong differences between the solutions $\mathrm{O}_{3}^{*}(T R)$ and the observed wave pattern, which helps to identify the additional processes that are not taken into account in the linear solution.

One reason for these differences might stem from an underestimation of vertical advection because of the quasigeostrophic approach, although a simple test with an artificial increase of $w_{\mathrm{b}}^{*}$ by a factor of 2 does not change the pattern of the solutions $\mathrm{O}_{3}^{*}(T R)$ substantially. Also, zonal asymmetries in eddy mixing processes due to transient wave activity, which cannot be derived from the Odin data alone, could contribute to the mean wave patterns. In particular, we assume a contribution of zonal asymmetries in eddy mixing processes due to baroclinic wave activity in the UTLS region, because they are particularly strong during winter and because their effect on temperature and ozone distribution is quite strong at these altitudes (e.g., Bartels et al., 1998; Gabriel and Schmitz, 2003).

Another reason for the differences between the observed field $\mathrm{O}_{3}^{*}$ and the calculated field $\mathrm{O}_{3}^{*}(T R)$ is that upper stratospheric ozone is more controlled by photochemistry and that non-linear interactions between wave perturbations in photochemistry and temperature largely determine the behaviour of upper stratospheric ozone (e.g., Douglass et al., 1985; Froidevaux et al., 1989; Brasseur and Solomon, 1995; Ward et al., 2010). In order to estimate the effect of these processes 

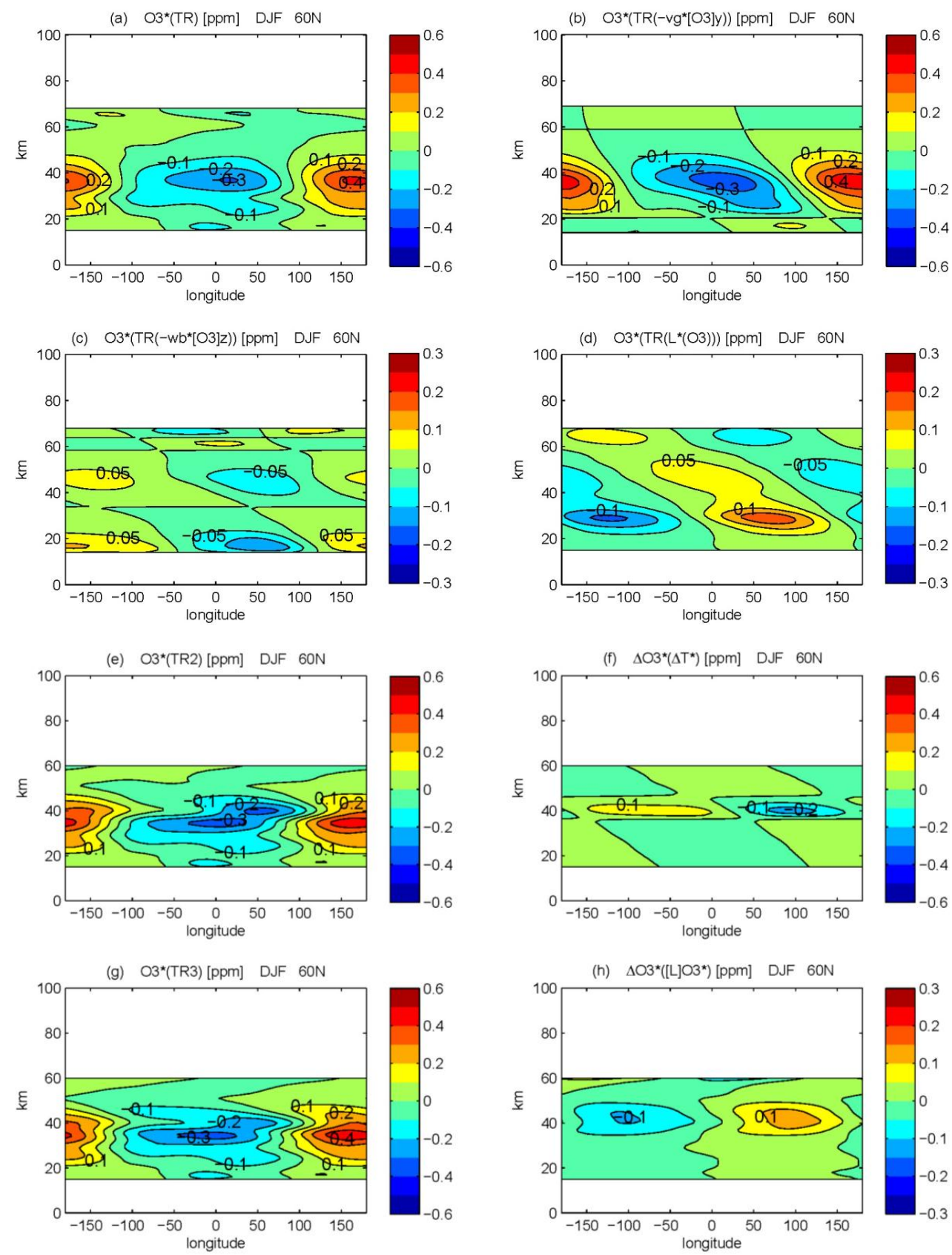

Fig. 5.1. (a-d): Linear solutions of the transport equation at $60^{\circ} \mathrm{N}$ for mean winter (DJF) of the time period 2001-2010, the figure shows the solutions $\mathrm{O}_{3}^{*}(T R)$ where the advection term $-\left[u_{\mathrm{g}}\right]\left(\mathrm{O}_{3}^{*}\right)_{x}$ is balanced by (a) the linear tendencies shown in Fig. $4.1 \mathrm{~b}$, c, d, (b) only the meridional advection of Fig. 4.1b, (c) only the vertical advection shown in Fig. 4.1c, and (d) only the chemical loss rates shown in Fig. 4.1d (details see Sect. 3.2); contour interval for (a) and (b): $0.1 \mathrm{ppmv}$, and for (c) and (d): 0.05 ppmv. (e-h): Effects on the distribution of zonally asymmetric ozone via interactions between wave perturbations in ozone photochemistry and temperature (upper panels) and via a mean loss of zonally asymmetric ozone (lower panels) at $60^{\circ} \mathrm{N}$ for mean northern winter (DJF) of the years 2001-2010, (e) calculated solution $\mathrm{O}_{3}^{*}(T R 2)=\mathrm{O}_{3}^{*}(T R)+\Delta \mathrm{O}_{3}^{*}\left(\Delta T^{*}\right)$ where $\mathrm{O}_{3}(T R)$ is the linear solution of Fig. 5.1a, (f) individual contribution $\Delta \mathrm{O}_{3}^{*}\left(\Delta T^{*}\right)$ due to ozone-temperature wave perturbations as derived from Eq. (8), (g) calculated solution $\mathrm{O}_{3}^{*}(T R 3)=\mathrm{O}_{3}^{*}(T R 2)+\Delta \mathrm{O}_{3}^{*}\left([L] \mathrm{O}_{3}^{*}\right)$ and (h) individual contribution $\Delta \mathrm{O}_{3}^{*}\left([L] \cdot \mathrm{O}_{3}^{*}(T R 2)\right)$ due to the loss term $[L] \cdot \mathrm{O}_{3}^{*}$ in the transport equation (Eq. 6) (details see section 3.2); contour interval for (e), (f) and (g): $0.1 \mathrm{ppmv}$, and for (h): $0.05 \mathrm{ppmv}$ (red colours refer to maximum positive values, blue colours refer to minimum negative values). 
we use an approach describing the relative sensitivity of ozone photochemistry to wave perturbations in temperature for photochemical equilibrium conditions based on the estimations of Froidevaux et al. (1989), Brasseur and Solomon (1995), and Ward et al. (2010):

$$
\frac{\Delta \mathrm{O}_{3}^{*}}{\left[\mathrm{O}_{3}\right]}=\left(\frac{\alpha}{\mathrm{P}_{H}}-\frac{\gamma}{[T]^{2}}\right) \Delta T^{*}
$$

Here, $\alpha$ is a radiative relaxation rate and $\mathrm{P}_{H}$ a time and zonal mean UV heating rate (we use $\alpha=0.2 \mathrm{~K} \mathrm{day}^{-1}$ and $P_{H}=10 \mathrm{~K} \mathrm{day}^{-1}$ for the altitude range $\left.30-60 \mathrm{~km}\right)$. For upper stratospheric altitudes the sensitivity parameter $\gamma$ has been derived based on photochemical model sensitivity studies and satellite observations (e.g., Froidevaux et al., 1989; Ward et al., 2010). According to Froidevaux et al. (1989) and Ward et al. (2010) we use values for $\gamma$ as given in Table 2 , including a slight adjustment in order to obtain an optimal improvement of the calculated $\mathrm{O}_{3}^{*}$ distribution at high midlatitudes.

Figure 5.1e, f shows the wave perturbation $\Delta \mathrm{O}_{3}^{*}\left(T^{*}\right)$ as derived via Eq. (8) based on the observed wave pattern $T^{*}$ and the zonal mean fields $\left[\mathrm{O}_{3}\right]$ and $[T]$ (Fig. 5.1f), and its effect on the configuration of the calculated stationary wave pattern as indicated by the resulting solution $\mathrm{O}_{3}^{*}(T R 2)=\mathrm{O}_{3}^{*}(T R)+\Delta \mathrm{O}_{3}^{*}\left(T^{*}\right)$ (Fig. 5.1e). Figure 5.1e, $\mathrm{f}$ shows that the amplitude $\Delta \mathrm{O}_{3}^{*}\left(T^{*}\right) \approx \pm 0.1-0.2 \mathrm{ppm}$ is comparable to the linear terms of Figure 5.1a-d but that both the maximum and the minimum of $\Delta \mathrm{O}_{3}^{*}\left(T^{*}\right)$ are located at upper stratospheric altitudes (at $\approx 40-45 \mathrm{~km}$ ). Therefore, it contributes significantly to the upper stratospheric part of the double-peak structure in $\mathrm{O}_{3}^{*}$ with the phase of $\Delta \mathrm{O}_{3}^{*}\left(T^{*}\right)$ being correlated to the phase of $T^{*}$.

Next we examine the feedback of $\mathrm{O}_{3}^{*}$ to the configuration of the stationary wave pattern via the loss term $[L] \mathrm{O}_{3}^{*}$. Figure $5.1 \mathrm{~h}$ shows the corresponding contribution $\Delta \mathrm{O}_{3}^{*}\left([L] \mathrm{O}_{3}^{*}\right)$ as a function of the mean loss rate $[L]$ and the solution $\mathrm{O}_{3}^{*}(T R 2)$, and Fig. 5.1g the improved solution $\mathrm{O}_{3}^{*}(T R 3)=\mathrm{O}_{3}^{*}(T R 2)+\Delta \mathrm{O}_{3}^{*}\left([L] \mathrm{O}_{3}^{*}\right.$. Figure $5.1 \mathrm{~h}$ shows that the effect of this feedback is located at upper stratospheric altitudes, as follows from the decrease of photochemical lifetime with height. This effect counteracts the effect of $\Delta \mathrm{O}_{3}^{*}\left(T^{*}\right)$ indicating a first-order photochemical equilibrium $\mathrm{P}^{*} \approx[L] \mathrm{O}_{3}^{*}+L^{*}\left[\mathrm{O}_{3}\right] \approx 0$ in the upper stratosphere, because of weak zonal asymmetries in the long-term mean of the production term $\mathrm{P}$ which is primarily the photolysis of $\mathrm{O}_{2}$. Figure $5.1 \mathrm{~g}$ shows that the inclusion of this loss term in the solution $\mathrm{O}_{3}^{*}(T R 3)$ leads to an additional improvement of the spatial structure in the upper stratosphere, i.e. the negative values in zonally asymmetric ozone mixing ratios of about $-0.1 \mathrm{ppm}$ over the Western Hemisphere (at around $60^{\circ}-$ $100^{\circ} \mathrm{W}$ and $40-45 \mathrm{~km}$ ) and positive values of about $0.2 \mathrm{ppm}$ over the Eastern Hemisphere (at $20^{\circ}-60^{\circ} \mathrm{E}$ and $40-45 \mathrm{~km}$ ) are closer to the observed structure than the mixing ratios of $\mathrm{O}_{3}^{*}(T R 2)$ at these altitudes.
Note here that the solution $\mathrm{O}_{3}^{*}(T R 3)$ is independent of the observed field $\mathrm{O}_{3}^{*}$, i.e., the processes analysed above reproduce a large part of the observed wave pattern. However, note also that the solution $\mathrm{O}_{3}^{*}(T R 3)$ is highly sensitive to the prescribed photochemical lifetime $\tau$ and the sensitivity parameter $\gamma$ which are adjusted to obtain optimal results, i.e., a variation of these parameters of about $10 \%$ leads to significantly less coherence of $\mathrm{O}_{3}^{*}(T R 3)$ with the observed wave pattern of $\mathrm{O}_{3}^{*}$. We conclude that more research is needed to clarify the role of the interactions between transport, temperature and photochemistry.

In the Southern Hemisphere, the fields $\mathrm{O}_{3}^{*}(T R)$ at $60^{\circ} \mathrm{S}$ (Fig. 5.2a), which include the effect of the tendencies due to advection by $v^{*}$ and $w^{*}$ and due to the linear loss term $-L^{*}(T)[\mu]$ analogously to Fig. 5.1a, show also a wave one pattern similar to those observed (compare with Fig. 1.2a), but only during southern spring (SON). The amplitude is weaker than that observed and the regions of pronounced values are spatially more concentrated to the middle stratosphere, indicating that additional contributions due to temperature-dependent photochemistry or eddy mixing processes are also important in configuring $\mathrm{O}_{3}^{*}$. Note here that the mean westerly flow $\left[u_{\mathrm{g}}\right]$ becomes easterly above $60 \mathrm{~km}$ during SON, therefore there occur no wave perturbations in $\mathrm{O}_{3}^{*}(T R)$ above these altitudes.

Analogously to the Northern Hemisphere, the inclusion of the parameterized wave perturbation $\Delta \mathrm{O}_{3}^{*}\left(T^{*}\right)$ leads to a slight improvement of upper stratospheric $\mathrm{O}_{3}^{*}(T R 2)$ (Fig. 5.2b), i.e. an extension of the wave pattern towards altitudes of about $40-45 \mathrm{~km}$ but with the phase being correlated to the wave one pattern in $T^{*}$. At least the inclusion of the loss term $[L] \mathrm{O}_{3}^{*}$, as indicated by the solutions $\mathrm{O}_{3}^{*}(T R 3)$ in Fig. 5.2c, leads to a slight modification of the wave pattern in the upper stratosphere and an extension of the minimum towards regions over the Western Hemisphere (at around $100^{\circ}-$ $150^{\circ} \mathrm{W}$ and $\left.40-45 \mathrm{~km}\right)$. However, there are still strong differences between the solution $\mathrm{O}_{3}^{*}(T R 3)$ and the observed fields indicating that additional effects contribute efficiently to the structure and amplitude of the stationary wave pattern.

In particular we have to consider that, below $\sim 25 \mathrm{~km}$, the effect of heterogeneous chemistry on Polar Stratospheric Cloud (PSC) droplets is much more efficient at the edge of the southern than of the northern polar vortex leading to strong ozone depletion within the polar vortex during southern spring when temperatures are very low (e.g., Solomon, 1999; WMO, 2007). Therefore zonal asymmetries in the southern polar vortex will contribute to the wave one pattern in $\mathrm{O}_{3}^{*}$ via zonal asymmetries in PSC occurrence and related heterogeneous chemistry. A similar contribution to the stationary wave one in ozone could be expected concerning zonal asymmetries in the northern polar vortex, although it should be weaker because temperatures inside the northern polar vortex are usually not as low as inside the southern polar vortex. As for the Northern Hemisphere, we may also expect a contribution of eddy mixing processes due to zonal 
(a) $\mathrm{O}^{\star}(\mathrm{TR})[\mathrm{ppm}] \mathrm{SON} 60 \mathrm{~S}$

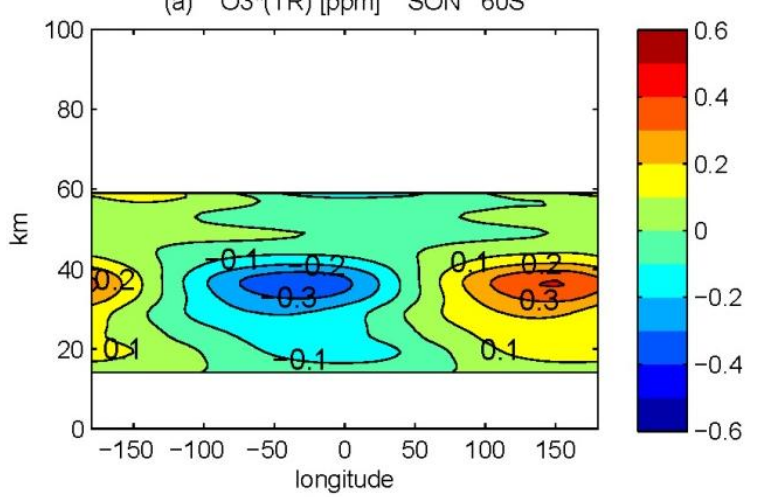

(b) $\mathrm{O}^{*}(\mathrm{TR} 2)[\mathrm{ppm}] \mathrm{SON} 60 \mathrm{~S}$

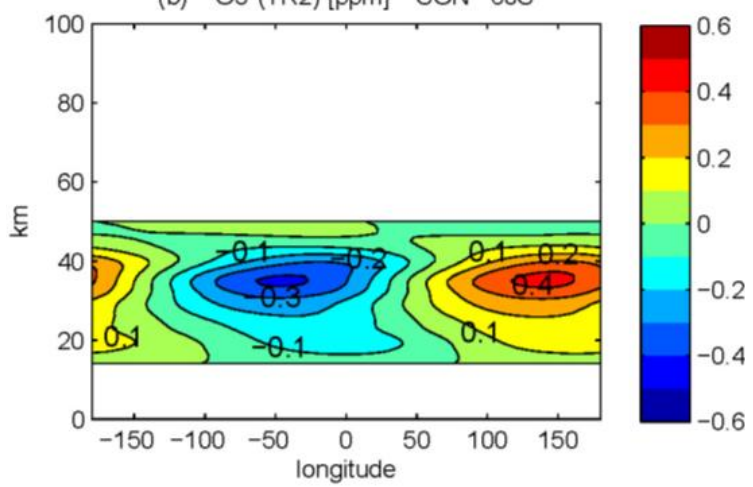

(c) $\mathrm{O}^{*}(\mathrm{TR} 3)[\mathrm{ppm}] \mathrm{SON} 60 \mathrm{~S}$

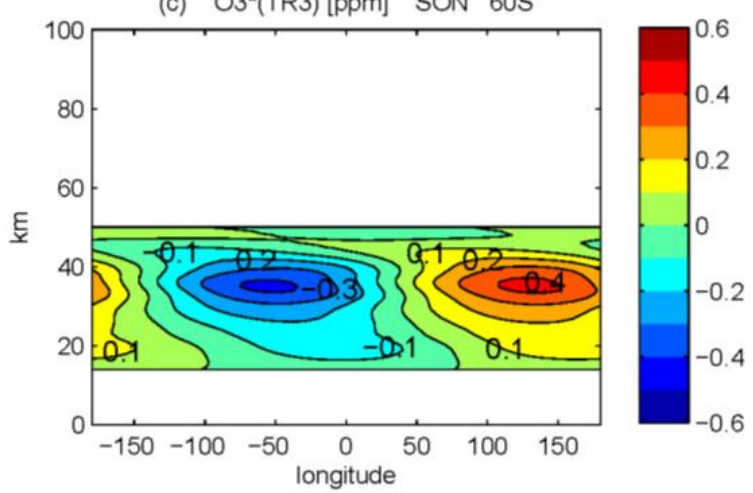

Fig. 5.2. (a): Linear solution $\mathrm{O}_{3}^{*}(T R)$ including tendencies analogously to Fig. $5.1 \mathrm{a}$, but at $60^{\circ} \mathrm{S}$ for mean southern spring (SON) (details see Sect. 3.2). (b-c): Effects on the distribution of zonally asymmetric ozone via interactions between wave perturbations in ozone photochemistry and temperature (bc) and via a mean loss of zonally asymmetric ozone (c), analogously to Fig. 5.1e, g but at $60^{\circ} \mathrm{S}$ for mean southern spring (SON) of the years 20012010, (b) solution $\mathrm{O}_{3}^{*}(T R 2)=\mathrm{O}_{3}^{*}(T R)+\Delta \mathrm{O}_{3}^{*}\left(\Delta T^{*}\right)$ where $\mathrm{O}_{3}(T R)$ is the linear solution of Figure 5.2a and $\Delta \mathrm{O}_{3}^{*}\left(\Delta T^{*}\right)$ the contribution due to ozone-temperature wave perturbations as derived from Eq. (8), and (c) solution $\mathrm{O}_{3}^{*}(T R 3)=\mathrm{O}_{3}^{*}(T R 2)+\Delta \mathrm{O}_{3}^{*}\left([L] \mathrm{O}_{3}^{*}\right)$ where $\Delta \mathrm{O}_{3}^{*}\left([\mathrm{~L}] \cdot \mathrm{O}_{3}^{*}(T R 2)\right)$ is the contribution due to the loss term $[L] \cdot \mathrm{O}_{3}^{*}$ in the transport equation (Eq. 6) (details see Sect. 3.2); contour interval: $0.1 \mathrm{ppmv}$ (red colours refer to maximum positive values, blue colours refer to minimum negative values). asymmetries in synoptic-scale baroclinic waves. However, the zonal asymmetries in transient wave activity are much less pronounced in the Southern than in the Northern Hemisphere because of the different land-sea distribution.

Figure 6.1 shows the linear solutions $\mathrm{H}_{2} \mathrm{O}^{*}(T R)$, together with the individual contributions of the tendencies at $60^{\circ} \mathrm{N}$ for northern winter. In comparison with the observed wave pattern (Fig. 2.b), Figs. 6.1a and 6.1b show that the spatial structure of $\mathrm{H}_{2} \mathrm{O}^{*}$ is primarily generated by the zonal asymmetries in the meridional transport, with the phase shift being related to the change in sign of the mean meridional $\left(\left[\mathrm{H}_{2} \mathrm{O}\right]_{y}\right)$ and vertical $\left(\left[\mathrm{H}_{2} \mathrm{O}\right]_{z}\right)$ gradients at upper stratosphere/lower mesosphere altitudes. Also the jump in phase at upper stratosphere altitudes is reproduced. The contribution of vertical advection to the wave pattern (Fig. 6.1c) is weaker, but intensifies the amplitude significantly in the lower and middle mesosphere. The effect of zonal asymmetries in the chemical loss rate due to depletion by $\mathrm{O}^{1} \mathrm{D}$ (Fig. 6.1c) is obviously not important as a primary source of the wave pattern.

Because of the long lifetime of $\mathrm{H}_{2} \mathrm{O}$ we find a better agreement between the spatial structure of $\mathrm{H}_{2} \mathrm{O}^{*}(T R)$ and the observed wave patterns than in case of $\mathrm{O}_{3}^{*}$, which seems to be more affected by zonal asymmetries in temperaturedependent chemistry at specific altitudes. However, as in the case of $\mathrm{O}_{3}^{*}$, the differences between $\mathrm{H}_{2} \mathrm{O}^{*}(T R)$ and the observed fields allow determining the underestimated or additional processes relevant for the generation of the wave pattern. For example, stronger vertical wind components than those derived by the quasi-geostrophic approximation may lead to an improvement of the amplitude in lower and middle mesosphere altitudes. As suggested by Smith (2003), quasistationary planetary wave patterns in the stratosphere induce zonal asymmetries in gravity wave propagation contributing to the quasi-stationary waves patterns in mesospheric geopotential. Associated zonal asymmetries in residual circulation and eddy mixing processes induced by gravity wave breaking may therefore also contribute to the wave pattern in mesospheric water vapour. As in case of $\mathrm{O}_{3}^{*}$, zonal asymmetries in eddy mixing processes due to tropospheric baroclinic wave activity may contribute to the amplitude of $\mathrm{H}_{2} \mathrm{O}^{*}$ in the lower stratosphere. In addition, zonal asymmetries in eddy mixing of tropospheric $\mathrm{CH}_{4}$ into stratosphere, which is the main source of stratospheric $\mathrm{H}_{2} \mathrm{O}$, could also have an influence on the amplitude of $\mathrm{H}_{2} \mathrm{O}^{*}$ in the lower stratosphere.

In the Southern Hemisphere, the fields $\mathrm{H}_{2} \mathrm{O}^{*}(T R)$ at $60^{\circ} \mathrm{S}$ (Fig. 6.2) show also a wave one pattern similar to the observed one (compare with Fig. 2.2a), but - as in case of $\mathrm{O}_{3}^{*}(T R)$ - with more pronounced amplitudes only during southern spring (SON) and less outspread, i.e. the regions of pronounced values are spatially more concentrated in the middle stratosphere and the lower mesosphere. In the lower stratosphere the amplitude of $\mathrm{H}_{2} \mathrm{O}^{*}(T R)$ is somewhat weaker than observed $(\sim 0.1 \mathrm{ppm}$ instead of $\sim 0.2 \mathrm{ppm}$ at $20-30 \mathrm{~km})$ but in the upper stratosphere/lower mesosphere somewhat stronger than observed $(\sim 0.2 \mathrm{ppm}$ instead of $\sim 0.1 \mathrm{ppm}$ at 

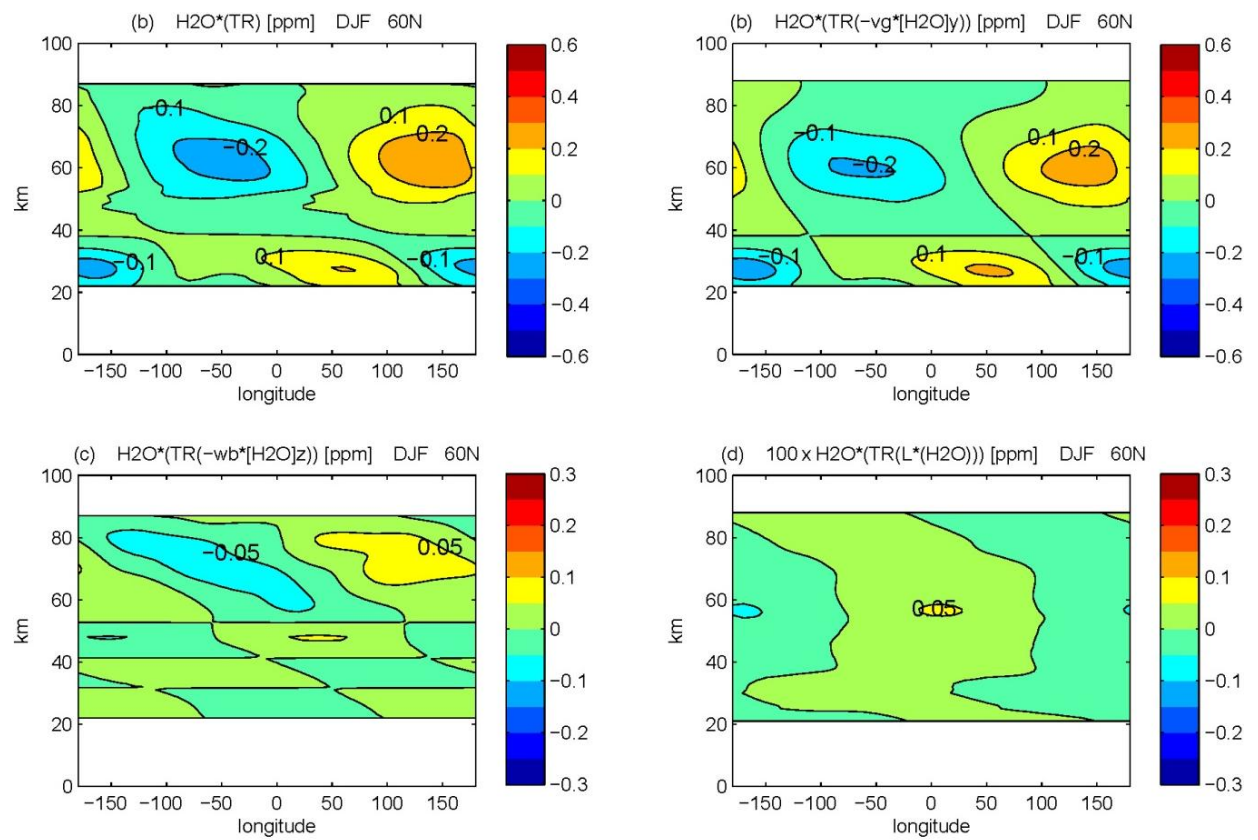

Fig. 6.1. Linear solutions of the transport equation at $60^{\circ} \mathrm{N}$ for mean winter (DJF) of the time period 2001-2010, (a) $\mathrm{H}_{2} \mathrm{O}^{*}(T R)$ including balance of $-\left[u_{\mathrm{g}}\right]\left(\mathrm{H}_{2} \mathrm{O}^{*}\right)_{x}$ by all of the other tendencies shown in Fig. 4.2, (b) including balance by only meridional advection of Fig. 4.2b, (c) including balance by only vertical advection shown in Fig. 4.2c, and (d) including balance by only chemical loss rates shown in Fig. 4.2d, also scaled by a factor of 100 (details see Sect. 3); contour interval for (a) and (b): 0.1 ppmv, and for (c) and (d): 0.05 ppmv (red colours refer to maximum positive values, blue colours refer to minimum negative values).

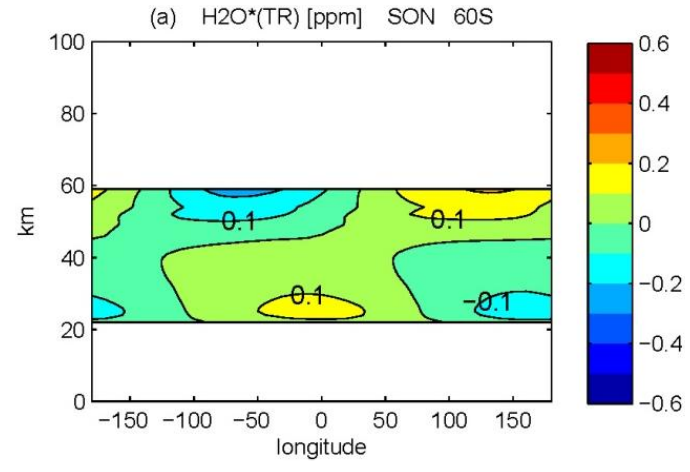

Fig. 6.2. (a): Linear solution $\mathrm{H}_{2} \mathrm{O}^{*}(T R)$ including all tendencies as in Fig. 6.1a, but at $60^{\circ} \mathrm{S}$ for mean southern spring (SON) (details see Sect. 3); contour interval: $0.1 \mathrm{ppmv}$ (red colours refer to maximum positive values, blue colours refer to minimum negative values).

50-60 km). Here we assume - as for the Northern Hemisphere winter - an additional effect of zonal asymmetries in eddy mixing processes which could contribute to the amplitude of $\mathrm{H}_{2} \mathrm{O}^{*}$ in the lower stratosphere. Eddy mixing processes might also lead to some damping of the wave one pattern at the upper stratosphere/lower mesosphere which is not captured by the linear solution. Note here again that the mean westerly flow $\left[u_{\mathrm{g}}\right]$ becomes easterly above $60 \mathrm{~km}$ dur- ing SON, therefore - as for $\mathrm{O}_{3}^{*}(T R)$ - no wave perturbations in $\mathrm{H}_{2} \mathrm{O}^{*}(T R)$ occur above these altitudes. More investigations are necessary to clarify the role of eddy mixing process in configuring the stationary wave patterns.

\section{Summary and discussion}

Based on long-term means of ozone and water vapour profiles derived from Odin satellite data 2001-2010, we find a pronounced wave one pattern in the zonally asymmetric components of both stratospheric ozone $\mathrm{O}_{3}^{*}=\mathrm{O}_{3}-\left[\mathrm{O}_{3}\right]$ and stratospheric and mesospheric water vapour $\mathrm{H}_{2} \mathrm{O}^{*}=\mathrm{H}_{2} \mathrm{O}$ $\left[\mathrm{H}_{2} \mathrm{O}\right]$ in the Northern and in the Southern Hemisphere $\left(\left[\mathrm{O}_{3}\right]\right.$, $\left[\mathrm{H}_{2} \mathrm{O}\right]$ : zonal means). In the Northern Hemisphere, the wave one patterns increase during autumn, maintain their strength during winter and decay during spring, with maximum amplitudes of about $10-20 \%$ of the zonal mean values. In the Southern Hemisphere, the wave one pattern develops mainly during southern spring.

Based on a linear solution of a steady-state transport equation for the zonally asymmetric component of a chemical tracer, including geostrophically balanced winds for advection, we show that the stationary wave patterns are primarily related to zonal asymmetries in the time mean of meridional transport by geostrophically balanced winds, in relation to the position, strength and spatial structure of the negative and 
positive anomalies in geopotential height (e.g., in relation to the northern winter polar low and Aleutian high anomalies). In particular, the linear solutions capture the phase of the wave one patterns in $\mathrm{O}_{3}^{*}$ and $\mathrm{H}_{2} \mathrm{O}^{*}$ during northern winter correctly, but underestimate their amplitudes. During southern spring, the amplitudes of the stationary wave one pattern in $\mathrm{O}_{3}^{*}$ and $\mathrm{H}_{2} \mathrm{O}^{*}$ are underestimated in the lower stratosphere but, in the case of $\mathrm{H}_{2} \mathrm{O}^{*}$, somewhat overestimated in the lower mesosphere. The observed double-peak structure in stratospheric $\mathrm{O}_{3}^{*}$ during northern winter with peak amplitudes in the lower and in the upper stratosphere is not reproduced by the transport tendencies alone.

The inclusion of the interaction of wave perturbations in ozone photochemistry and temperature via a sensitivity parameter $\gamma$, which is prescribed according to the estimations of Froidevaux et al. (1989), Brasseur and Solomon (1995) and Ward et al. (2010), and the inclusion of the feedback of $\mathrm{O}_{3}^{*}$ to the stationary wave pattern via the zonally asymmetric chemical loss term $[L] \mathrm{O}_{3}^{*}$ (where $[L]$ is prescribed in terms of photochemical lifetime according to Brasseur and Solomon, 1995) leads to a better reproduction of the wave pattern in upper stratospheric ozone. In particular, the observed double-peak structure in stratospheric $\mathrm{O}_{3}^{*}$ is better reproduced if these processes are taken into account. However, the resulting solution is highly sensitive to the prescribed photochemical lifetime $\tau$ and the sensitivity parameter $\gamma$, which are slightly adjusted to obtain an optimal solution of the transport equation in comparison to the observed field. We conclude that more research is needed to clarify the role of the interactions between transport, temperature and photochemistry.

The differences between the linear solutions and the observed fields as well as the analysis of the involved individual tendencies enable us to determine additional processes contributing to the configuration of the stationary wave patterns. For example, the quasi-geostrophic approach of the winds might lead to an underestimation of the amplitude due to the lack of zonally asymmetric transport by nongeostrophic winds. Zonal asymmetries in eddy mixing due to synoptic-scale baroclinic waves or small-scale gravity waves might also be important. The feedbacks of the temperaturedependent non-linear catalytic $\mathrm{NO}_{x^{-}}, \mathrm{HO}_{x^{-}}, \mathrm{ClO}_{\mathrm{x}}-$ and $\mathrm{BrO}_{\mathrm{x}}$ ozone destruction cycles to the stationary wave pattern might be stronger than can be captured by the linear parameterizations used for the solution of the transport equation.

In particular one has to consider that zonal asymmetries in baroclinic wave activity and associated eddy mixing processes in the UTLS region may contribute to the mean amplitude of both $\mathrm{O}_{3}^{*}$ and $T^{*}$ in the lower stratosphere, consistent with the observed correlation between changes in ozone and temperature at these altitudes. For the lower stratosphere we can also assume that the feedback of temperature-dependent chlorine and bromine chemistry could enhance the amplitudes of the stationary wave patterns in $\mathrm{O}_{3}^{*}$ in case of a preexisting stationary wave pattern in temperature and chem- ical species, i.e. in case of a zonally asymmetric configuration of the cold winter polar vortex. In the middle and upper stratosphere, zonal asymmetries in the temperaturedependent and highly non-linear $\mathrm{NO}_{\mathrm{x}}$ chemistry may contribute to the mean amplitude of $\mathrm{O}_{3}^{*}$, as has been shown recently for ozone changes in case of a major sudden stratospheric warming event (Flury et al., 2009). Therefore, the combination of the zonal asymmetries in eddy tracer fluxes in the lower stratosphere and in $\mathrm{NO}_{\mathrm{x}}$ chemistry in the upper stratosphere could further modulate the spatial structure of $\mathrm{O}_{3}^{*}$, modifying the primary wave one pattern generated by geostrophically-balanced advection and linear temperaturedependent photochemistry towards the observed double-peak structure of $\mathrm{O}_{3}^{*}$. During southern spring the effect of heterogeneous chemistry on Polar Stratospheric Cloud (PSC) droplets on chemical ozone depletion processes at altitudes below $\sim 25 \mathrm{~km}$ is much more efficient at the edge of the southern than of the northern polar vortex, which might contribute additionally to the wave one pattern in $\mathrm{O}_{3}^{*}$ in case of a zonally asymmetric polar vortex.

For the wave patterns in $\mathrm{H}_{2} \mathrm{O}^{*}$ one has to consider that the zonal asymmetries in eddy mixing of tropospheric $\mathrm{CH}_{4}$ into the lower stratosphere might contribute additionally to the mean amplitude of lower stratospheric $\mathrm{H}_{2} \mathrm{O}^{*}$. On the other hand, zonal asymmetries in gravity wave breaking and associated zonal asymmetries in eddy mixing and residual circulation might contribute additionally to the mean amplitude in mesospheric $\mathrm{H}_{2} \mathrm{O}^{*}$. Stronger vertical winds than those derived from the quasi-geostrophic balanced approximation would lead to an improvement of the wave patterns derived via the linear solution of the transport equation. However, reliable wind estimates from data assimilation systems remain challenging for the stratosphere and mesosphere (Polavarapu et al., 2005).

\section{Conclusions}

Based on Odin satellite data 201-2010 we find stationary wave one patterns in stratospheric ozone and middle atmospheric water vapour with maximum amplitudes of about 10 $20 \%$ of the zonal mean mixing ratios during winter. The amplitude and the spatial structure of these wave patterns are primarily due to the zonally asymmetric advection by geostrophically balanced winds, and, in the case of upper stratospheric ozone, by temperature-dependent photochemistry. Additionally, zonal asymmetries in eddy mixing processes might play an important role in determining the observed stationary wave patterns, but a detailed assessment of the eddy tracer fluxes cannot be derived from the Odin satellite data alone.

The stationary planetary wave patterns derived from the satellite data are a suitable indicator of the processes generating these patterns, i.e. of zonal asymmetries in meridional transport and temperature-dependent chemistry. It is 

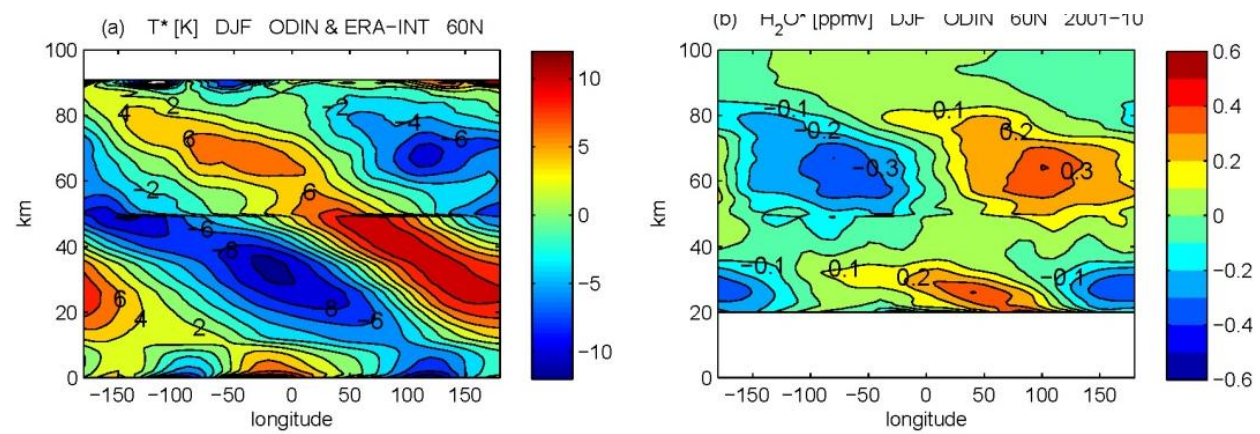

Fig. A1. Long-term means of zonally asymmetric components of (a) temperature $T^{*}$ (isolines in $\mathrm{K}$ ), (b) water vapour $\mathrm{H}_{2} \mathrm{O}^{*}$ (isolines in ppm) at $60^{\circ} \mathrm{N}$ for northern winter (DJF) of the time period 2001-2010, but without applying the matching procedure at $50 \mathrm{~km}$ altitude as described in Sect. 2.1 (note the thin perturbation line at $50 \mathrm{~km}$ altitude) (red colours refer to maximum positive values, blue colours refer to minimum negative values).

important to understand and to quantify these processes because they play a key role in understanding longitudinal differences in wave-driven transport and in the atmospheric circulation, and because they provide an important validation tool for predictions with general circulation models (GCMs) and chemistry-climate models (CCMs) used in the framework of ozone depletion and climate change studies. Quantifying the stationary wave patterns in ozone and water vapour based on model-independent data may also be important because of the feedbacks to wave propagation and atmospheric circulation via the induced radiation perturbations, as suggested by a number of recent model studies (Gabriel et al., 2007; Crook et al., 2008; Gillett et al., 2009; Waugh et al., 2009). Our results therefore suggest further investigations of the processes generating the stationary wave patterns based on both observations and CCMs.

\section{Appendix A}

It is an open question whether the matching procedure at stratopause altitudes, which is described in Sect. 2.1 and applied for two Odin data sets for stratospheric and mesospheric $\mathrm{H}_{2} \mathrm{O}$ and for the two data sets of the Odin and the ERA Interim temperature profiles, could have an effect on the results for $\mathrm{H}_{2} \mathrm{O}^{*}$ and $T^{*}$ presented in the paper.

For comparison, Fig. A1a shows the vertically unsmoothed field of $\mathrm{H}_{2} \mathrm{O}^{*}$ at $60^{\circ} \mathrm{N}$ without applying this matching procedure, revealing only a thin perturbation line at $50 \mathrm{~km}$ which indicates that the two fields of $\mathrm{H}_{2} \mathrm{O}^{*}$ derived from the two Odin data sets do not match exactly. Additionally, Fig. A1b shows the vertically unsmoothed field $T^{*}$ at $60^{\circ} \mathrm{N}$ without applying this matching procedure, revealing a thin perturbation line at $50 \mathrm{~km}$ which indicates that the data sets of Odin and ERA Interim do not match exactly. In comparison to Figs. 2.1b and 3.1a there are also some more perturbations which are filtered out as noise. However, all of these changes do not affect the large-scale wave one pattern extending from troposphere up to the top of the mesosphere.
Acknowledgements. Odin is a Swedish-led satellite project funded jointly by the Swedish National Space Board (SNSB), the Canadian Space Agency (CSA), the National Technology Agency of Finland (Tekes) and the Centre National d'Etudes Spatiales (CNES) in France. The Swedish Space Corporation has been the industrial prime constructor. Since April 2007 Odin is a third-party mission of ESA. We thank the ECMWF who provided the ERA-40 data. We thank also two anonymous referees for helpful comments and suggestions. The work of the presented paper was supported by the International Meteorological Institute in Stockholm (IMI), and by the Deutsche Forschungsgemeinschaft under grant PE-474/5).

Edited by: W. Lahoz

\section{References}

Andrews, D. G., J. R. Holton and C. B. Leovy: Middle Atmosphere Dynamics, International Geophysical Series, Academic Press, 40, 489 pp., 1987.

Austin, J. and Butchart, N.: A 3-dimensional modeling study of the influence of planetary wave dynamics on polar ozone photochemistry. J. Geophys. Res. 97, pp. 10165-10186, 1992.

Bartels, J., Peters, D., and Schmitz, G.: Climatological Ertel's potential-vorticity flux and mean meridional circulation in the extratropical troposphere - lower stratosphere. Ann. Geophys., 16, 250-265, doi:10.5194/angeo-16-250-1998, 1998.

Brasseur, G. and Solomon, S.: Aeronomy of the Middle Atmosphere, D. Reidel Publishing Company, Dordrecht, The Netherlands, 445 pp., 1995.

Charney, J. and Drazin, P.: Propagation of planetary-scale disturbances from the lower into the upper atmosphere, J. Geophys. Res., 66, 83-109, 1961.

Coy, L., Štajner, I., DaSilva, A. M., Joiner, J., Rood, R. B., Pawson, S., and Lin, S. J.: High-Frequency Planetary Waves in the Polar Middle Atmosphere as Seen in a Data Assimilation System, J. Atmos. Sci., 60, 2975-2992, 2003.

Crook, J. A., Gillett, N. P., and Keeley, S. P. E.: Sensitivity of Southern Hemisphere climate to zonal asymmetry in ozone, Geophys. Res. Lett., 35, L07806, doi:10.1029/2007GL032698, 2008. 
Douglass, A. R., Rood, R. B., and Stolarski, R. S.: Interpretation of Ozone Temperature Correlations 2. Analysis of SBUV Ozone Data, J. Geophys. Res., 90, 10693-10708, 1985.

Flury, T., Hocke, K., Haefele, A., Kämpfer, N., and Lehmann, R.: Ozone depletion, water vapor increase, and PSC generation at midlatitudes by the 2008 major stratospheric warming. J. Geophys. Res., 114, D18302, doi:10.1029/2009JD011940, 2009.

Froidevaux, L., Allen, M., Berman, S., and Daughton, A.: The Mean Ozone Profile and Its Temperature Sensitivity in the Upper Stratosphere and Lower Mesosphere: An Analysis of LIMS Observations, J. Geophys. Res., 94, 6389-6417, 1989.

Gabriel, A. and Schmitz, G.: The Influence of Large-Scale Eddy Flux Variability on the Zonal Mean Ozone Distribution, J. Climate, 16, 2615-2627, 2003.

Gabriel, A., Peters, D., Kirchner, I., and Graf, H.-F.: Effect of zonally asymmetric ozone on stratospheric temperature and planetary wave propagation, Geophys. Res. Lett., 34, L06807, doi:10.1029/2006GL028998, 2007.

Garcia, R. and Hartmann, D.: The role of planetary waves in the maintenance of the zonally averaged ozone distribution of the upper stratosphere, J. Atmos. Sci., 37, 2248-2264, 1980.

Gillett, N. P., Scinocca, J. F., Plummer, D. A., and Reader, M. C.: Sensitivity of climate to dynamically consistent zonal asymmetries in ozone, Geophys. Res. Lett., 36, L10809, doi:10.1029/2009GL037246, 2009.

Haklander, A. J., Siegmund, P. C., Sigmond, M., and Kelder, H. M.: How does the northern-winter wave driving of the Brewer-Dobson circulation increase in an enhancedCO2 climate simulation?, Geophys. Res. Lett., 35, L07702, doi:10.1029/2007GL033054, 2008.

Holton, J. R.: Meridional distribution of stratospheric trace gas constituents, J. Atmos. Sci, 43, 1238-1243, 1986.

Holton, J. R. and Gettelman, A.: Horizontal transport and the dehydration of the stratosphere, Geophys. Res. Lett., 28, 2799-2802, 2001.

Hood, L. and Zaff, D.: Lower stratospheric stationary waves and the longitude dependence of ozone trends in winter, J. Geophys. Res., 100, 25791-25800, 1995.

Jones, A., Urban, J., Murtagh, D. P., Eriksson, P., Brohede, S., Haley, C., Degenstein, D., Bourassa, A., von Savigny, C., Sonkaew, T., Rozanov, A., Bovensmann, H., and Burrows, J.: Evolution of stratospheric ozone and water vapour time series studied with satellite measurements, Atmos. Chem. Phys., 9, 6055-6075, doi:10.5194/acp-9-6055-2009, 2009.

Joshi, M. M., Charlton, A. J., and Scaife, A. A.: On the influence of stratospheric water vapour changes on the tropospheric circulation, Geophys. Res. Lett., 33, L09806, doi:10.1029/2006GL025983, 2006.

Kinnersley, J. S. and Tung, K.-K.: Modeling the Global Interannual Variability of Ozone Due to the Equatorial QBO and to Extratropical Planetary Wave Variability, J. Atmos. Sci., 55, 14171428, 1998.

Karpetchko, A., Kyro, E., and Knudsen, B. M.: Arctic and Antarctic polar vortices 1957-2002 as seen from the ERA-40 reanalyses, J. Geophys. Res., 110, D21109, doi:10.1029/2005JD006113, 2005.

Kirchner, I. and Peters, D.: Modeling the wintertime response to upper tropospheric and lower stratospheric ozone anomalies over the North Atlantic and Europe, Ann. Geophys., 21, 2107-2118, doi:10.5194/angeo-21-2107-2003, 2003.
Lossow, S., Urban, J., Eriksson, P., Murtagh, D., and Gumbel, J.: Critical parameters for the retrieval of mesospheric water vapour and temperature from Odin/SMR limb measurements at $557 \mathrm{GHz}$, Adv. Space Res., 40, 835-845, 2007.

Lossow, S., Urban, J., Gumbel, J., Eriksson, P., and Murtagh, D.: Observations of the mesospheric semi-annual oscillation (MSAO) in water vapour by Odin/SMR, Atmos. Chem. Phys., 8, 6527-6540, doi:10.5194/acp-8-6527-2008, 2008.

Lossow, S., Urban, J., Schmidt, H., Marsh, D. R., Gumbel, J., Eriksson, P., and Murtagh, D.: Wintertime water vapor in the polar upper mesosphere and lower thermosphere: First satellite observations by Odin submillimeter radiometer, J. Geophys. Res., 114, D10304, doi:10.1029/2008JD011462, 2009.

Mote, P. W. and Dunkerton, T. J.: Kelvin wave signatures in stratospheric trace constituents, J. Geophys. Res., 109, D03101, doi:10.1029/2002JD003370, 2004.

Murtagh, D., Frisk, U., Merino, F., Ridal, M., Jonsson, A., Stegman, J., Witt, G., Eriksson, P., Jimenez, C., Mégie, G., de La Noëë, J., Ricaud, P., Baron, P., Pardo, J.-R., Hauchecorne, A., Llewellyn, E. J., Degenstein, D. A., 5 Gattinger, R. L., Lloyd, N. D., Evans, W. F. J., Mc-Dade, I. C., Haley, C., Sioris, C., von Savigny, C., Solheim, B. H., McConnell, J. C., Strong, K., Richardson, E. H., Leppelmeier G. W., , Kyrölä, E., Auvinen H., and Oikarinen, L.: An overview of the Odin Atmospheric Mission, Can. J. Phys., 80, 309-319, 2002.

Nathan, T. R., Cordero, E. C., and Li, L.: Ozone heating and the destabilization of traveling waves during summer, Geophys. Res. Lett., 21, 1531-1534, 1994.

Peters, D. and Entzian, G.: January ozone anomaly over the North Atlantic-European region: Longitude-dependent decadal change in the total ozone during 1079-92, Meteorol. Zeitschrift, 5, 4144, 1996.

Peters, D. and Entzian, G.: Longitude-dependent decadal changes of total ozone in boreal winter months during 1979-92, J. Climate, 12, 1038-1048, 1999.

Peters, D. H. W., Gabriel, A., and Entzian, G.: Longitudedependent decadal ozone changes and ozone trends in boreal winter months during 1960-2000, Ann. Geophys., 26, 12751286, doi:10.5194/angeo-26-1275-2008, 2008.

Polavarapu, S., Shepherd, T. G., Rochon, Y., and Ren, S.: Some challenges of middle atmosphere data assimilation, Q. J. Roy. Meteorol. Soc., 131, 3513-3527, 2005.

Randel, W. J.: Kelvin Wave-Induced Trace Constituent Oscillations in the Equatorial Stratosphere, J. Geophys. Res., 95, 1864118652, 1990.

Randel, W. J.: Global Normal-Mode Rossby Waves Observed in Stratospheric Ozone Data, J. Atmos. Sci., 50, 406-420, 1993.

Randel, W. J., Wu, F., Russell III, J. M., Roche, A., and Waters, J. W.: Seasonal cycles and QBO variations in stratospheric $\mathrm{CH}_{4}$ and $\mathrm{H}_{2} \mathrm{O}$ observed in UARS HALOE data, J. Atmos. Sci., 55, 163-185, 1998.

Rood, R. B. and Douglass, A. R.: Interpretation of ozone temperature correlations, 1, Theory, J. Geophys. Res., 90, 5733-5744, 1985.

Sassi, F., Boville, B. A., Kinnison, D., and Garcia, R. R.: The effects of interactive ozone chemistry on simulations of the middle atmosphere, Geophys. Res. Lett., 32, L07811, doi:10.1029/2004GL022131, 2005.

Smith, A. K.: The Origin of Stationary Planetary Waves in the Up- 
per Mesosphere. J. Atmos. Sci., 60, 3033-3041, 2003.

Solomon, S.: Stratospheric ozone depletion: A review of concepts and history, Rev. Geophys., 37, 275-316, 1999.

Solomon, S., Portmann, R. W., Garcia, R. R., Randel, W., Wu, F., Nagatani, R., Gleason, J., Thomason, L., Poole, L. R., and McCormick, M. P.: Ozone depletion at midlatitudes: Coupling of volcanic aerosols and temperature variability to anthropogenic chlorine, Geophys. Res. Lett., 25, 1871-1874, 1998.

SPARC Assessment of Upper Tropospheric and Stratospheric Water Vapour, edited by: Kley, D., Russell III, J. M., and Phillips, C., SPARC Report No. 2, WCRP - 113, WMO/TD - No. 1043, http: //www.atmosp.physics.utoronto.ca/SPARC, 2000.

Stolarski, R. S. and Douglass, A. R.: Parameterization of the photochemistry of stratospheric ozone including catalytic loss processes, J. Geophys. Res., 90, 10709-10718, 1985.

Sun, C.-R. and Leovy, C.: Ozone Variability in the Equatorial Middle Atmosphere, J. Geophys. Res., 95, 13829-13849, 1990.

Tung, K.-K.: On the Two-Dimensional Transport of Stratospheric Trace Gases in Isentropic Coordinates, J. Atmos. Sci., 39, 23302355, 1982.

Urban, J., Lautié, N., Le Flochmoën, E., Jiménez, C., Eriksson, P., de La Noëë, J., Dupuy, E., Ekström, M., El Amraoui, L., Frisk, L. U., Murtagh, D., Olberg M., and Ricaud, P.: Odin/SMR 5 limb observations of stratospheric trace gases: Level 2 processing of $\mathrm{ClO}, \mathrm{N}_{2} \mathrm{O}, \mathrm{HNO}_{3}$, and $\mathrm{O}_{3}$, J. Geophys. Res., 110, D14307, doi:10.1029/2004JD005741, 2005.

Urban, J., Lautié, N., Murtagh, D. P., Eriksson, P., Kasai, Y., Lossow, S., Dupuy, E., de La Noëë, J., Frisk, U., Olberg, M., Le Flochmoën, E., Ricaud, P.: Global observations of middle atmospheric water vapour by the Odin satellite: An overview., Planet. Space Sci., 55, 1093-1102, 2007.
Visconti, G. and Pitari, G.: Seasonal and Latitudinal Distribution of Trace Gases in the Stratosphere: Results from a 2-D Residual Circulation Model, J. Atmos. Chem., 5, 255-289, 1987.

Wang, D. Y., von Clarmann, T., Fischer, H., Funke, B., GarcíaComas, M., Gil-López, S., Glatthor, N., Grabowski, U., Höpfner, M., Kellmann, S., Kiefer, M., Koukouli, M. E., Lin, G., Linden, A., López-Puertas, M., Mengistu Tsidu, G., Milz, M., Steck, T., and Stiller, G. P.: Longitudinal variations of temperature and ozone profiles observed by MIPAS during the Antarctic stratosphere sudden warming of 2002, J. Geophys. Res., 110, D20101, doi:10.1029/2004JD005749, 2005.

Ward, W. E., Oberheide, J., Riese, M., Preusse, P., and Offermann, D.: Planetary wave two signatures in CRISTA 2 ozone and temperature data, in Atmospheric Science Across the Stratopause, edited by: Siskind, D. E., Eckermann, S. D., and Summers, M. E., 319-325, 2000.

Waugh, D. W. and Randel, W. J.: Climatology of Arctic and Antarctic polar vortices using elliptical diagnostics, J. Atmos. Sci., 56 , 1594-1613, 1999.

Waugh, D. W., Oman, L., Newman, P. A., Stolarski, R. S., Pawson, S., Nielsen, J. E., and Perlwitz, J.: Effect of zonal asymmetries in stratospheric ozone on simulated Southern Hemisphere climate trends, Geophys. Res. Lett., 36, L18701, doi:10.1029/2009GL040419, 2009.

WMO (World Meteorological Organization) 2007: Scientific Assessment of Ozone Depletion: 2006, Global Ozone Research and Monitoring Project - Report No. 50, 572 pp., Geneva, 2007. 